\title{
Synthesis and Characterization of compounds
}

Reagents were acquired from Fischer, Scharlab and Sigma, and Milli-Q (MQ) water $(18.3 \Omega)$ was used in all the steps.

Synthesis and Characterization of the glycodendropeptide D $_{1}$ GIcNAc-o-OE (D3) and the corresponding synthetic intermediates
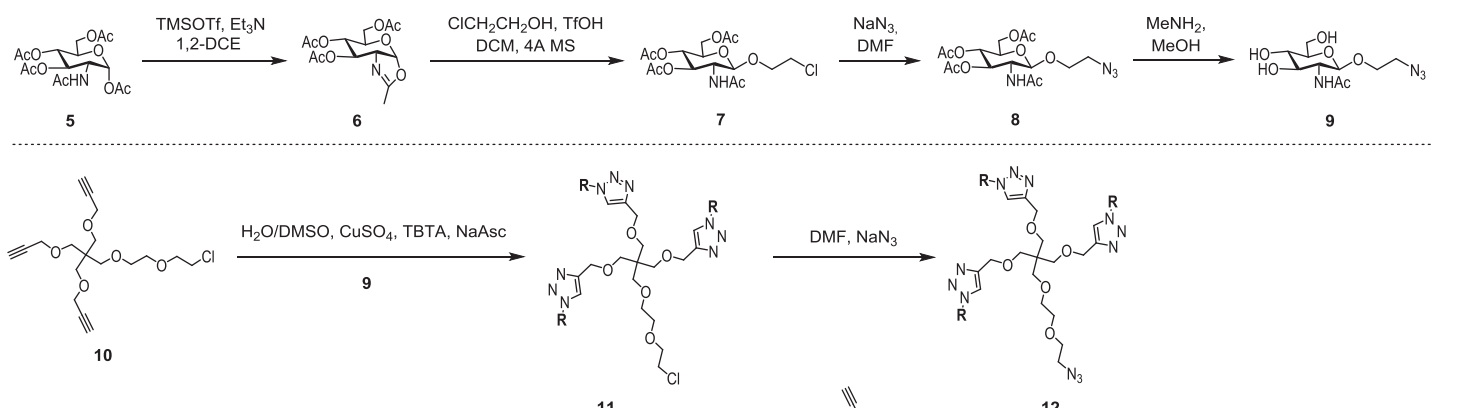

$$
R={ }_{H O}^{\text {HO }} \underset{\text { NHAC }}{\frac{F_{0}^{O H}}{O}}
$$
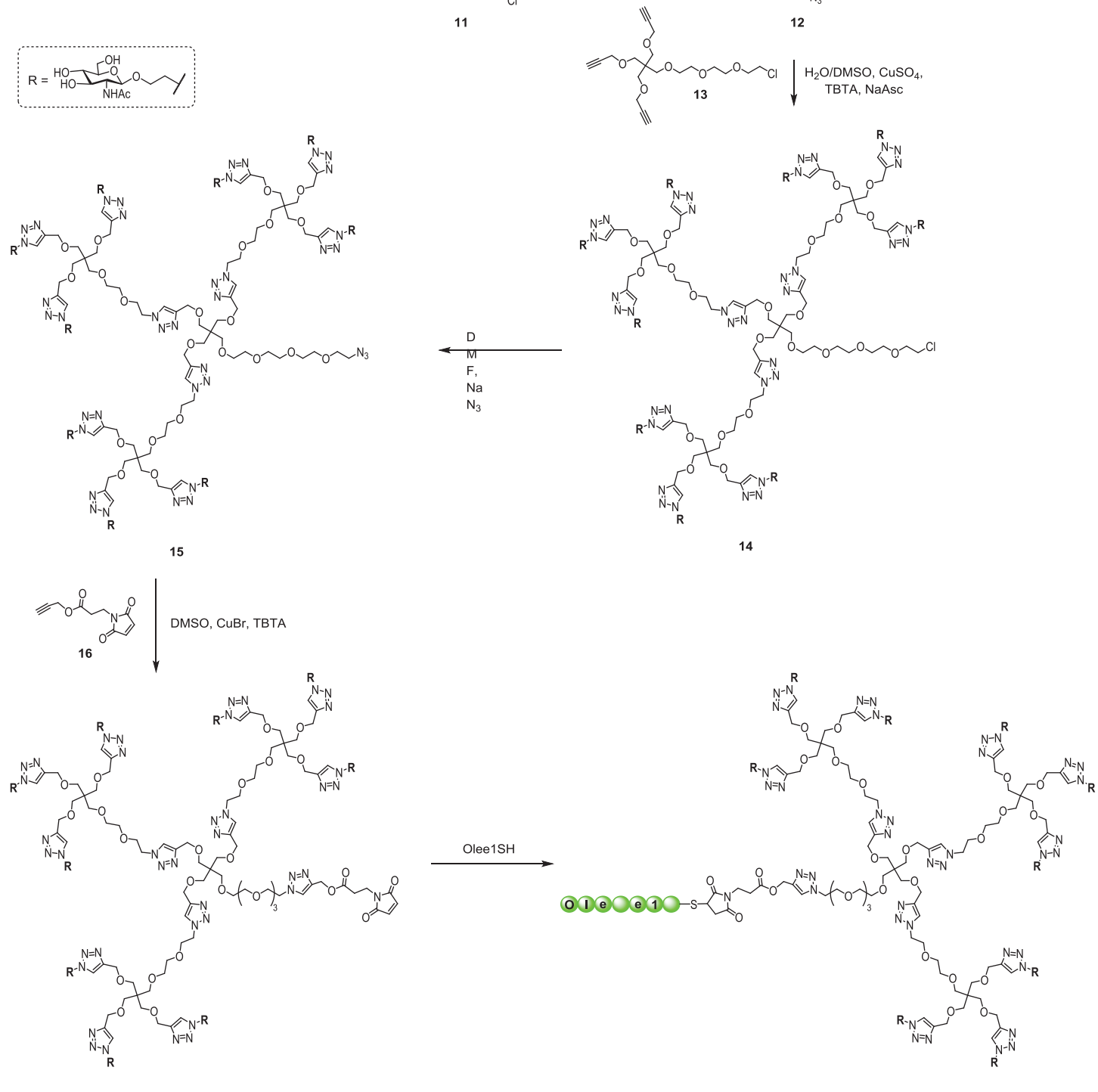

Figure S1. Synthetic scheme for the preparation of glycodendropeptide $\mathrm{D}_{1}$ GlcNAc-O-OE (D3). 


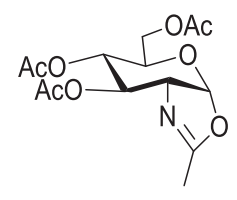

To a solution of peracetylated sugar 5[i] $(10 \mathrm{~g}, 25.70 \mathrm{mmol})$ in dry 1,2-dichloroethane $(80 \mathrm{~mL})$, TMSOTf (4.9 $\mathrm{mL}, 26.98 \mathrm{mmol})$ was added at room temperature. The mixture was stirred for $4 \mathrm{~h}$ at $50^{\circ} \mathrm{C}$, cooled and treated with triethylamine $(2.9 \mathrm{~mL})$. After $15 \mathrm{~min}$ at room temperature, the reaction mixture was diluted with $\mathrm{CH}_{2} \mathrm{Cl}_{2}$ and washed with a $\mathrm{NaHCO}_{3}$ sat. aq. soln. The organic layer was dried over anh. $\mathrm{MgSO}_{4}$, filtered and concentrated under vacuum. The residue was purified by column chromatography on silica gel $\left(\mathrm{CHCl}_{3} / \mathrm{MeOH}, 30: 1 \rightarrow 20: 1\right)$, afforded $6(8.45 \mathrm{~g}, 25.68 \mathrm{mmol}$, quant.) as a yellow oil. $[\alpha]_{\mathrm{D}}^{20}:+15\left(c 1.00, \mathrm{CHCl}_{3}\right) ;{ }^{1} \mathrm{H}-\mathrm{NMR}\left(400 \mathrm{MHz}, \mathrm{CDCl}_{3}\right) 5.96\left(\mathrm{~d}, 1 \mathrm{H}, J_{1,2}=\right.$ 7.4, H-1), 5.26 (t, $1 \mathrm{H}, J=2.4, \mathrm{H}-3), 4.92\left(\mathrm{ddd}, 1 \mathrm{H}, J_{4,5}=9.3, J_{4,3}=2.1, J_{4,2}=1.2, \mathrm{H}-4\right)$, 4.17 (m, 2H, H-6), 4.13 (m, 1H, H-2), 3.60 (m, 1H, H-5), 2.10 (s, 3H, $\mathrm{CH}_{3}$ of OAc), 2.09 (s, $3 \mathrm{H}, \mathrm{CH}_{3}$ of $\mathrm{OAc}$ ), $2.08\left(\mathrm{~d}, 3 \mathrm{H}, J_{\mathrm{H}, 2}=2.1, \mathrm{CH}_{3}\right.$ of oxazoline), 2.07 (s, 3H, $\mathrm{CH}_{3}$ of OAc); ${ }^{13} \mathrm{C}-\mathrm{NMR}\left(100 \mathrm{MHz}, \mathrm{CDCl}_{3}\right) 170.5$ (CO), 169.5 (CO), 169.1 (CO), 166.6 (CNoxazoline), 99.3 (C-1), 70.3 (C-3), 68.3 (C-4), 67.5 (C-5), 64.9 (C-2), 63.3 (C-6), 20.9 ( $\mathrm{CH}_{3}$ of OAc), 20.8 ( $\mathrm{CH}_{3}$ of OAc), 20.7 ( $\mathrm{CH}_{3}$ of OAc), $13.9\left(\mathrm{CH}_{3}\right.$ of oxazoline); ESI-MS $m / z$ calcd. for $\mathrm{C}_{14} \mathrm{H}_{19} \mathrm{NO}_{3}$ : 329.1; found: $352.1[\mathrm{M}+\mathrm{Na}]^{+}$; ESI-HRMS m/z calcd. for $\mathrm{C}_{14} \mathrm{H}_{20} \mathrm{NO}_{8}[\mathrm{M}+\mathrm{H}]^{+}: 330.1183$; found: 330.1172 .

\section{2-Chloroethyl 2-acetamido-3,4,6-tri- $O$-acetyl-2-deoxy- $\beta$-D-glucopyranose (7).}

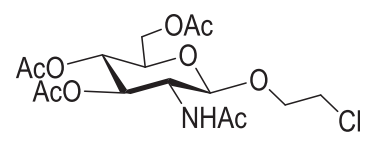

To a mixture of oxazoline $6(5.45 \mathrm{~g}, 16.56 \mathrm{mmol})$ and powdered $4 \AA$ molecular sieves in dry $\mathrm{CH}_{2} \mathrm{Cl}_{2}(120 \mathrm{~mL})$, freshly distilled 2-chloroethanol $(11.2 \mathrm{~mL}, 165.60 \mathrm{mmol})$ was added. The reaction vessel was sealed, heated at $60^{\circ} \mathrm{C}$ and trifluoromethanesulfonic acid $(598 \mu \mathrm{L}, 6.62 \mathrm{mmol})$ was added. The reaction mixture was heated at $60^{\circ} \mathrm{C}$ for $4 \mathrm{~h}$. After this period, the mixture was cooled, filtered through celite and washed with $\mathrm{CH}_{2} \mathrm{Cl}_{2}$. The organic layer was washed with $\mathrm{NaHCO}_{3}$ sat. aq. soln. and brine. The organic phase was 
dried over anh. $\mathrm{MgSO}_{4}$, filtered and concentrated under vacuum to remove the excess of 2-chloroethanol. The residue was purified by column chromatography on silica gel $\left(\mathrm{CHCl}_{3} / \mathrm{MeOH}, 100: 0 \rightarrow 100: 1\right)$, afforded 7 (6.00 g, $\left.14.67 \mathrm{mmol}, 89 \%\right)$ as a white solid. $[\alpha]_{\mathrm{D}}^{20}:-9\left(c 1.00, \mathrm{CHCl}_{3}\right) ;{ }^{1} \mathrm{H}-\mathrm{NMR}\left(400 \mathrm{MHz}, \mathrm{CDCl}_{3}\right) 5.60\left(\mathrm{~d}, 1 \mathrm{H}, J_{\mathrm{NH}, 2}=8.6, \mathrm{NH}\right), 5.36$ $\left(\mathrm{dd}, 1 \mathrm{H}, J_{4,3}=3.4, J_{4,5}=0.9, \mathrm{H}-4\right), 5.30\left(\mathrm{dd}, 1 \mathrm{H}, J_{3,2}=11.2, \mathrm{H}-3\right), 4.80\left(\mathrm{~d}, 1 \mathrm{H}, J_{1,2}=8.4\right.$, H-1), 4.20-4.08 (m, 3H, H-6, H-1'a), 4.02-3.90 (m, 2H, H-2, H-5), 3.79 (m, 1H, H-1 'b), $3.64\left(\mathrm{dd}, 2 \mathrm{H}, J_{2}{ }^{\prime}, 1^{\prime} \mathrm{b}=6.3, J_{2}{ }^{\prime},{ }^{\prime} \mathrm{a}=5.0, \mathrm{H}-2^{\prime}\right), 2.14\left(\mathrm{~s}, 3 \mathrm{H}, \mathrm{CH}_{3}\right.$ of OAc), $2.04\left(\mathrm{~s}, 3 \mathrm{H}, \mathrm{CH}_{3}\right.$ of OAc), 2.00 (s, 3H, $\mathrm{CH}_{3}$ of OAc), $1.96\left(\mathrm{~s}, 3 \mathrm{H}, \mathrm{CH}_{3}\right.$ of $\left.\mathrm{NHAc}\right) ;{ }^{13} \mathrm{C}-\mathrm{NMR}(100 \mathrm{MHz}$, $\left.\mathrm{CDCl}_{3}\right) 170.8$ (CO), 170.6 (CO), 170.5 (CO), 170.4 (CO), 101.3 (C-1), 70.9 (C-5), 69.8 (C-1'), 69.7 (C-3), 66.9 (C-4), 61.6 (C-6), 51.5 (C-2), 43.1 (C-2'), 23.5 ( $\mathrm{CH}_{3}$ of NHAc), $20.8\left(\mathrm{CH}_{3}\right.$ of OAc); ESI-MS m/z calcd. for $\mathrm{C}_{16} \mathrm{H}_{24} \mathrm{ClNO}_{9}: 409.1$; found: $432.1[\mathrm{M}+\mathrm{Na}]^{+}$; ESI-HRMS $m / z$ calcd. for $\mathrm{C}_{16} \mathrm{H}_{24} \mathrm{ClNO}_{9} \mathrm{Na}[\mathrm{M}+\mathrm{Na}]^{+}$: 432.1032; found: 432.1025 .

\section{2-Azidoethyl 2-acetamido-3,4,6-tri-O-acetyl-2-deoxy- $\beta$-D-glucopyranose (8).}

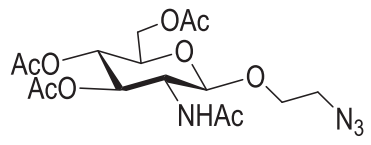

To a solution of the chloro derivative $7(5.8 \mathrm{~g}, 14.18 \mathrm{mmol})$ in DMF (60 mL), $\mathrm{NaN}_{3}(4.6$ g, $70.88 \mathrm{mmol}$ ) was added, and the mixture was stirred at $70^{\circ} \mathrm{C}$ for $38 \mathrm{~h}$. After evaporation of the solvent, the residue was diluted with $\mathrm{CH}_{2} \mathrm{Cl}_{2}$, filtered through celite, washed several times with $\mathrm{CH}_{2} \mathrm{Cl}_{2}$ and concentrated, to give the compound $\mathbf{8}$ (5.82 g, $13.99 \mathrm{mmol}$, quant.) as a white solid. $[\alpha]_{\mathrm{D}}^{20}:-30\left(c 1.00, \mathrm{CHCl}_{3}\right) ;{ }^{1} \mathrm{H}-\mathrm{NMR}\left(400 \mathrm{MHz}, \mathrm{CDCl}_{3}\right) 5.57$ (d, 1H, $\left.J_{\mathrm{NH}, 2}=8.4, \mathrm{NH}\right), 5.41-5.34$ (m, 2H, H-3, H-4), 4.86 (d, $\left.1 \mathrm{H}, J_{1,2}=8.4, \mathrm{H}-1\right), 4.15$ (m, 2H,

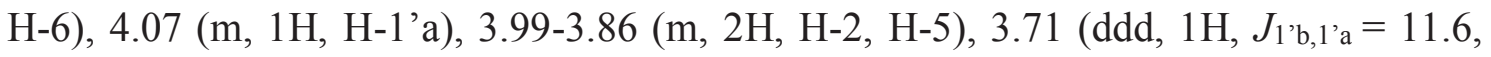
$\left.J_{1}{ }^{\prime} \mathrm{b}, 2^{\prime} \mathrm{a}=8.7, J_{1}{ }^{\prime}, 2^{\prime} \mathrm{b}=3.1, \mathrm{H}-1{ }^{\prime} \mathrm{b}\right), 3.52\left(\mathrm{ddd}, 1 \mathrm{H}, J_{2}{ }^{\prime}, 2^{\prime} \mathrm{b}=13.3, J_{2}{ }^{\prime} \mathrm{a}, 1^{\prime} \mathrm{a}=3.2, J_{2}{ }^{\prime} \mathrm{b}, 1^{\prime} \mathrm{b}=3.1\right.$, H-2'a), 3.27 (ddd, $\left.1 \mathrm{H}, J_{2}{ }^{\prime} \mathrm{b}, 2^{\prime} \mathrm{a}=13.3, J_{2}{ }^{\prime} \mathrm{b}, 1^{\prime} \mathrm{a}=4.6, J^{\prime}{ }^{\prime} \mathrm{b}, 1^{\prime} \mathrm{b}=3.1, \mathrm{H}-2^{\prime} \mathrm{b}\right), 2.14\left(\mathrm{~s}, 3 \mathrm{H}, \mathrm{CH}_{3}\right.$ of $\mathrm{OAc}$ ), 2.04 (s, 3H, $\mathrm{CH}_{3}$ of OAc), 2.00 (s, 3H, $\mathrm{CH}_{3}$ of OAc), $1.96\left(\mathrm{~s}, 3 \mathrm{H}, \mathrm{CH}_{3}\right.$ of $\mathrm{NHAc}$ ); ${ }^{13} \mathrm{C}-\mathrm{NMR}\left(100 \mathrm{MHz}, \mathrm{CDCl}_{3}\right) 170.8$ (CO), 170.5 (CO), 170.4 (CO), 170.3 (CO), 100.7 (C-1), 70.8 (C-5), 69.7 (C-3), 68.2 (C-1'), 66.9 (C-4), 61.6 (C-6), 51.4 (C-2), 50.6 (C-2'), $23.4\left(\mathrm{CH}_{3}\right.$ of NHAc), $20.7\left(\mathrm{CH}_{3}\right.$ of OAc); ESI-MS $m / z$ calcd. for $\mathrm{C}_{16} \mathrm{H}_{24} \mathrm{~N}_{4} \mathrm{O}_{9}$ : 416.2; found: $439.2[\mathrm{M}+\mathrm{Na}]^{+}$; ESI-HRMS $m / z$ calcd. for $\mathrm{C}_{16} \mathrm{H}_{24} \mathrm{~N}_{4} \mathrm{O} 9 \mathrm{Na}[\mathrm{M}+\mathrm{Na}]^{+}$: 439.1435 ; found: 439.1430 . 


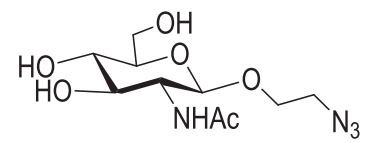

The peracetylated sugar $8(5.8 \mathrm{~g}, 13.94 \mathrm{mmol})$ was dissolved in $2 \mathrm{M}$ methylamine solution in $\mathrm{MeOH}(50 \mathrm{~mL})$, and the mixture was stirred at room temperature for $3 \mathrm{~h}$. After evaporation of the solvent, the residue was suspended with toluene. The solid was filtered, washed several times with ether and dried under high vaccum to give the compound 9 (4.0 g, $13.79 \mathrm{mmol}$, quant.) as a white solid. $[\alpha]_{\mathrm{D}}^{20}:-27\left(c\right.$ 1.00, $\left.\mathrm{H}_{2} \mathrm{O}\right) ;{ }^{1} \mathrm{H}-\mathrm{NMR}(400 \mathrm{MHz}$, $\left.\mathrm{D}_{2} \mathrm{O}\right) 4.60\left(\mathrm{~d}, 1 \mathrm{H}, J_{1,2}=8.4, \mathrm{H}-1\right), 4.07\left(\mathrm{ddd}, 1 \mathrm{H}, J_{1}{ }^{\prime} \mathrm{a}, 1^{\prime} \mathrm{b}=11.4, J_{1}{ }^{\prime} \mathrm{a},{ }^{\prime} \mathrm{a}=5.5, J_{1}{ }^{\prime} \mathrm{a},{ }^{\prime} \mathrm{b}=3.1\right.$, H-1'a), 3.94 (dd, 1H, $\left.J_{6 \mathrm{a}, 6 \mathrm{~b}}=12.2, J_{6 \mathrm{a}, 5}=1.6, \mathrm{H}-6 \mathrm{a}\right), 3.83-3.70$ (m, 3H, H-1'b, H-2, H6b), 3.56 (m, 1H, H-3), 3.52-3.39 (m, 4H, H-2', H-4, H-5), 2.06 (s, 3H, $\mathrm{CH}_{3}$ of NHAc); ${ }^{13} \mathrm{C}-\mathrm{NMR}\left(100 \mathrm{MHz}, \mathrm{D}_{2} \mathrm{O}\right) 174.5$ (CO), 101.0 (C-1), 75.9 (C-5), 73.9 (C-3), 70.0 (C-4), 68.7 (C-1'), 60.8 (C-6), 55.5 (C-2), 50.4 (C-2'), 22.4 ( $\mathrm{CH}_{3}$ of NHAc); ESI-MS m/z calcd. for $\mathrm{C}_{10} \mathrm{H}_{18} \mathrm{~N}_{4} \mathrm{O}_{6}$ : 290.1; found: $313.2[\mathrm{M}+\mathrm{Na}]^{+}$; ESI-HRMS $m / z$ calcd. for $\mathrm{C}_{10} \mathrm{H}_{18} \mathrm{~N}_{4} \mathrm{O}_{6} \mathrm{Na}$ $[\mathrm{M}+\mathrm{Na}]^{+}: 313.1119$; found: 313.1115 .

\section{Glycodendron 11.}

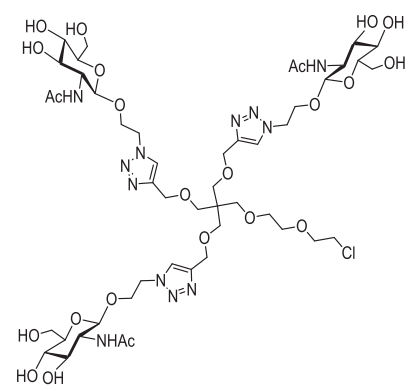

2-Azidoethyl 2-acetamido-2-deoxy- $\beta$-D-glucopyranose (9) (344 mg, $1.15 \mathrm{mmol}$ ), compound 10[ii] (114 mg, $0.32 \mathrm{mmol}), \mathrm{CuSO}_{4} \cdot 5 \mathrm{H}_{2} \mathrm{O}$ (24 mg, $\left.0.10 \mathrm{mmol}\right)$, TBTA (105 $\mathrm{mg}, 0.19 \mathrm{mmol}$ ) and sodium ascorbate $\left(58 \mathrm{mg}, 0.29 \mathrm{mmol}\right.$ ) were dissolved in $\mathrm{H}_{2} \mathrm{O} / \mathrm{DMSO}$ $(1: 1,3 \mathrm{~mL})$ in a sealed microwaves vial. The solution was heated at $60^{\circ} \mathrm{C}$ in a microwaves oven for $30 \mathrm{~min}$. A metal scavenger resin, QuadrasilMP, was added to the reaction solution and stirred for $15 \mathrm{~min}$ at room temperature. After that, the mixture was filtered 
and the resulting solution was purified by size-exclusion chromatography (Sephadex LH20, $\mathrm{MeOH} 100 \%$ ), furnishing the glycodendron 11 (389 mg, $0.32 \mathrm{mmol}$, quant.) as a white amorphous solid. ${ }^{1} \mathrm{H}-\mathrm{NMR}$ (400 MHz, CD $\mathrm{OD}$ ) 7.93 (s, 3H, $\mathrm{H}_{\text {triazole }}$ ), 4.59 (m, 6H, $\left.\mathrm{OCH}_{2} \mathrm{CH}_{2} \mathrm{~N}\right), 4.53\left(\mathrm{~s}, 6 \mathrm{H}, \mathrm{OCH}_{2} \mathrm{C}_{\text {triazole }}\right), 4.43\left(\mathrm{~d}, 3 \mathrm{H}, J_{1,2}=8.4, \mathrm{H}-1\right), 4.24(\mathrm{~m}, 3 \mathrm{H}$, $\left.\mathrm{OCHHCH}_{2} \mathrm{~N}\right), 3.96-3.85$ (m, 6H, OCH $\left.\mathrm{HCH}_{2} \mathrm{~N}, \mathrm{H}-6 \mathrm{a}\right), 3.74-3.58\left(\mathrm{~m}, 12 \mathrm{H}, \mathrm{CH}_{2} \mathrm{CH}_{2} \mathrm{Cl}\right.$, $\left.\mathrm{H}-6 \mathrm{~b}, \mathrm{H}-2, \mathrm{CH}_{2} \mathrm{Cl}, \mathrm{CH}_{2} \mathrm{O}\right), 3.53$ (m, 2H, $\left.\mathrm{CH}_{2} \mathrm{O}\right), 3.49$ (s, 6H, $\left.\mathrm{CCH}_{2} \mathrm{O}\right), 3.47-3.41$ (m, 5H, $\mathrm{H}-3, \mathrm{CCH}_{2} \mathrm{OCH}_{2} \mathrm{CH}_{2} \mathrm{O}$ ), 3.31 (under $\left.\mathrm{CD}_{3} \mathrm{OD}, 3 \mathrm{H}, \mathrm{H}-4\right), 3.29$ (m, 3H, H-5), 1.92 (s, 9H, $\mathrm{CH}_{3}$ of $\left.\mathrm{NHAc}\right) ;{ }^{13} \mathrm{C}-\mathrm{NMR}\left(100 \mathrm{MHz}, \mathrm{CD}_{3} \mathrm{OD}\right) 173.6(\mathrm{CO}), 145.8$ (C $\left.\mathrm{C}_{\text {triazole }}\right), 125.9$ $\left(\mathrm{CH}_{\text {triazole }}\right), 102.4(\mathrm{C}-1), 77.9(\mathrm{C}-5), 75.7(\mathrm{C}-3), 72.3\left(\mathrm{CH}_{2} \mathrm{CH}_{2} \mathrm{Cl}\right), 72.0\left(\mathrm{CH}_{2} \mathrm{O}\right), 71.9(\mathrm{C}-$ 4), $71.2\left(\mathrm{CH}_{2} \mathrm{O}\right), 70.7\left(\mathrm{CCH}_{2} \mathrm{OCH}_{2} \mathrm{CH}_{2} \mathrm{O}\right), 70.1\left(\mathrm{CCH}_{2} \mathrm{O}\right), 68.3\left(\mathrm{OCH}_{2} \mathrm{CH}_{2} \mathrm{~N}\right), 65.3$ $\left(\mathrm{OCH}_{2} \mathrm{C}_{\text {triazole }}\right), 62.6(\mathrm{C}-6), 56.9(\mathrm{C}-2), 51.4\left(\mathrm{OCH}_{2} \mathrm{CH}_{2} \mathrm{~N}\right), 46.5\left(\mathrm{CCH}_{2} \mathrm{O}\right), 44.1\left(\mathrm{CH}_{2} \mathrm{Cl}\right)$, $23.3\left(\mathrm{CH}_{3}\right.$ of NHAc); ESI-MS $\mathrm{m} / z$ calcd. for $\mathrm{C}_{48} \mathrm{H}_{79} \mathrm{ClN}_{12} \mathrm{O}_{23}$ : 1226.5; found: 1249.4 $[\mathrm{M}+\mathrm{Na}]^{+}, 633.2[\mathrm{M}+\mathrm{K}+\mathrm{H}]^{+2}$; ESI-HRMS $m / z$ calcd. for $\mathrm{C}_{48} \mathrm{H}_{79} \mathrm{ClN}_{12} \mathrm{O}_{23} \mathrm{Na}[\mathrm{M}+\mathrm{Na}]^{+}$: 1249.4962; found: 1249.4953 .

\section{Glycodendron 12.}

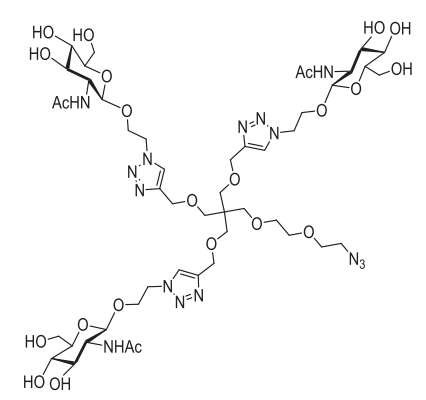

To a solution of glycodendron $11(357 \mathrm{mg}, 0.29 \mathrm{mmol})$ in DMF (10 mL) was added sodium azide ( $189 \mathrm{mg}, 2.91 \mathrm{mmol})$. The mixture was stirred at $60^{\circ} \mathrm{C}$ for 3 days. After that time, the solvent was concentrated and the crude was purified by size-exclusion chromatography (Sephadex LH-20, MeOH 100\%), furnishing the glycodendron 12 (352 mg, $0.29 \mathrm{mmol}, 98 \%$ ) as a white amorphous solid. ${ }^{1} \mathrm{H}-\mathrm{NMR}\left(400 \mathrm{MHz}, \mathrm{CD}_{3} \mathrm{OD}\right) 7.93$ (s, $\left.3 \mathrm{H}, \mathrm{H}_{\text {triazole }}\right), 4.58\left(\mathrm{~m}, 6 \mathrm{H}, \mathrm{OCH}_{2} \mathrm{CH}_{2} \mathrm{~N}\right), 4.53\left(\mathrm{~s}, 6 \mathrm{H}, \mathrm{OCH}_{2} \mathrm{C}_{\text {triazole }}\right), 4.43\left(\mathrm{~d}, 3 \mathrm{H}, J_{1,2}=\right.$ 8.4, H-1), 4.24 (m, 3H, OCH $\left.\mathrm{HCH}_{2} \mathrm{~N}\right), 3.96-3.85$ (m, 6H, OCH $\left.\mathrm{HCH}_{2} \mathrm{~N}, \mathrm{H}-6 \mathrm{a}\right), 3.72-3.63$ (m, 8H, H-6b, H-2, $\left.\mathrm{CH}_{2} \mathrm{CH}_{2} \mathrm{~N}_{3}\right), 3.59$ (m, 2H, $\left.\mathrm{CH}_{2} \mathrm{O}\right), 3.53\left(\mathrm{~m}, 2 \mathrm{H}, \mathrm{CH}_{2} \mathrm{O}\right), 3.49$ (s, 6H, $\mathrm{CCH}_{2} \mathrm{O}$ ), 3.47-3.41 (m, 5H, H-3, $\mathrm{CCH}_{2} \mathrm{OCH}_{2} \mathrm{CH}_{2} \mathrm{O}$ ), 3.34 (m, $2 \mathrm{H}, \mathrm{CH}_{2} \mathrm{~N}_{3}$ ), 3.31 (under $\left.\mathrm{CD}_{3} \mathrm{OD}, 3 \mathrm{H}, \mathrm{H}-4\right), 3.29$ (m, 3H, H-5), 1.92 (s, 9H, $\mathrm{CH}_{3}$ of NHAc); ${ }^{13} \mathrm{C}-\mathrm{NMR}(100 \mathrm{MHz}$, $\left.\mathrm{CD}_{3} \mathrm{OD}\right) 173.6(\mathrm{CO}), 145.8$ ( $\left.\mathrm{C}_{\text {triazole }}\right), 125.9\left(\mathrm{CH}_{\text {triazole }}\right), 102.4(\mathrm{C}-1), 77.9$ (C-5), 75.7 (C3), $72.1\left(\mathrm{CH}_{2} \mathrm{O}\right), 71.9(\mathrm{C}-4), 71.3\left(\mathrm{CH}_{2} \mathrm{O}\right), 71.1\left(\mathrm{CH}_{2} \mathrm{CH}_{2} \mathrm{~N}_{3}\right), 70.7\left(\mathrm{CCH}_{2} \mathrm{OCH}_{2} \mathrm{CH}_{2} \mathrm{O}\right)$, 
$70.1\left(\mathrm{CCH}_{2} \mathrm{O}\right), 68.4\left(\mathrm{OCH}_{2} \mathrm{CH}_{2} \mathrm{~N}\right), 65.3\left(\mathrm{OCH}_{2} \mathrm{C}_{\text {triazole }}\right), 62.7(\mathrm{C}-6), 56.9(\mathrm{C}-2), 51.7$ $\left(\mathrm{CH}_{2} \mathrm{~N}_{3}\right), 51.3\left(\mathrm{OCH}_{2} \mathrm{CH}_{2} \mathrm{~N}\right), 46.5\left(\mathrm{CCH}_{2} \mathrm{O}\right), 23.3\left(\mathrm{CH}_{3}\right.$ of NHAc); ESI-MS $\mathrm{m} / z$ calcd. for $\mathrm{C}_{48} \mathrm{H}_{79} \mathrm{~N}_{15} \mathrm{O}_{23}$ : 1233.5; found: $1256.5[\mathrm{M}+\mathrm{Na}]^{+}$; ESI-HRMS $\mathrm{m} / z$ calcd. for $\mathrm{C}_{48} \mathrm{H}_{79} \mathrm{~N}_{15} \mathrm{O}_{23} \mathrm{Na}[\mathrm{M}+\mathrm{Na}]^{+}:$1256.5365; found: 1256.5350 .

\section{Glycodendron 14.}

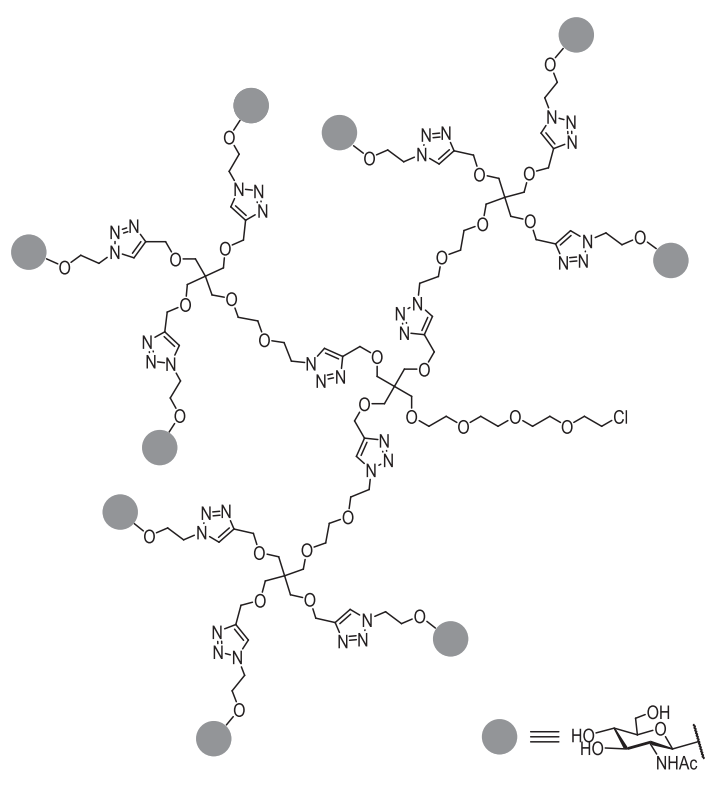

Glycodendron 12 (270 mg, $0.22 \mathrm{mmol}$ ), compound 13[iii] (27 mg, $60.78 \mu \mathrm{mol})$, $\mathrm{CuSO}_{4} \cdot 5 \mathrm{H}_{2} \mathrm{O}(4.6 \mathrm{mg}, 18.24 \mu \mathrm{mol})$, TBTA $(20 \mathrm{mg}, 36.47 \mu \mathrm{mol})$ and sodium ascorbate (11 mg, $54.71 \mu \mathrm{mol})$ were dissolved in $\mathrm{H}_{2} \mathrm{O} / \mathrm{DMSO}(1: 1,1.5 \mathrm{~mL})$ in a sealed microwaves vial. The solution was heated at $60^{\circ} \mathrm{C}$ in a microwaves oven for $30 \mathrm{~min}$. A metal scavenger resin, QuadrasilMP, was added to the reaction solution and stirred for $15 \mathrm{~min}$ at room temperature. After that, the mixture was filtered and the resulting solution was purified by size-exclusion chromatography (Sephadex G-25, $\mathrm{H}_{2} \mathrm{O} / \mathrm{MeOH} 9 / 1$ ), furnishing the glycodendron 14 (242 mg, $58.39 \mu \mathrm{mol}, 96 \%$ ) as a white amorphous solid. ${ }^{1} \mathrm{H}-\mathrm{NMR}$ (400 $\left.\mathrm{MHz}, \mathrm{D}_{2} \mathrm{O}\right) 7.97$ (s, 3H, $\left.\mathrm{H}_{\text {triazole }}\right), 7.94$ (s, 9H, $\left.\mathrm{H}_{\text {triazole }}\right), 4.63-4.51\left(\mathrm{~m}, 42 \mathrm{H}, \mathrm{OCH}_{2} \mathrm{CH}_{2} \mathrm{~N}\right.$, $\mathrm{O}_{\text {linker }} \mathrm{CH}_{2} \mathrm{CH}_{2} \mathrm{~N}, \mathrm{OCH}_{2} \mathrm{C}_{\text {triazole }}$ ), 4.53 (br s, $6 \mathrm{H}, \mathrm{OCH}_{2} \mathrm{C}_{\text {triazole }}$ ), 4.46 (d, 9H, $J_{1,2}=8.4, \mathrm{H}-$ 1), $4.28\left(\mathrm{~m}, 9 \mathrm{H}, \mathrm{OCHHCH}_{2} \mathrm{~N}\right), 4.01\left(\mathrm{~m}, 9 \mathrm{H}, \mathrm{OCHHCH}_{2} \mathrm{~N}\right), 3.95-3.87(\mathrm{~m}, 15 \mathrm{H}$, $\left.\mathrm{O}_{\text {linker }} \mathrm{CH}_{2} \mathrm{CH}_{2} \mathrm{~N}, \mathrm{H}-6 \mathrm{a}\right), 3.79-3.58$ (m, 30H, H-2, H-6b, $\left.\mathrm{CH}_{2} \mathrm{Cl}, \mathrm{CH}_{2} \mathrm{O}\right), 3.57-3.36$ (m, $\left.67 \mathrm{H}, \mathrm{H}-3, \mathrm{H}-4, \mathrm{H}-5, \mathrm{CCH}_{2} \mathrm{O}, \mathrm{CH}_{2} \mathrm{O}\right), 3.33\left(\mathrm{~m}, 8 \mathrm{H}, \mathrm{CCH}_{2} \mathrm{OCH}_{2} \mathrm{CH}_{2} \mathrm{O}\right), 1.85\left(\mathrm{~s}, 27 \mathrm{H}, \mathrm{CH}_{3}\right.$ of NHAc); ${ }^{13} \mathrm{C}-\mathrm{NMR}\left(100 \mathrm{MHz}, \mathrm{D}_{2} \mathrm{O}\right) 173.9(\mathrm{CO}), 144.1$ ( $\left.\mathrm{C}_{\text {triazole }}\right), 144.0\left(\mathrm{C}_{\text {triazole }}\right), 125.2$ ( $\left.\mathrm{CH}_{\text {triazole }}\right), 125.1$ ( $\left.\mathrm{CH}_{\text {triazole }}\right), 100.9(\mathrm{C}-1), 75.9$ (C-5), $73.6(\mathrm{C}-3), 70.8\left(\mathrm{CH}_{2} \mathrm{CH}_{2} \mathrm{Cl}\right), 70.5$ $\left(\mathrm{CH}_{2} \mathrm{O}\right), 70.4\left(\mathrm{CH}_{2} \mathrm{O}\right), 69.9(\mathrm{C}-4), 69.6\left(\mathrm{CH}_{2} \mathrm{O}\right), 69.5\left(\mathrm{CH}_{2} \mathrm{O}\right), 69.2\left(\mathrm{CCH}_{2} \mathrm{OCH}_{2} \mathrm{CH}_{2} \mathrm{O}\right)$, 
$69.0\left(\mathrm{CCH}_{2} \mathrm{OCH}_{2} \mathrm{CH}_{2} \mathrm{O}\right), 68.7\left(\mathrm{O}_{\text {linker }} \mathrm{CH}_{2} \mathrm{CH}_{2} \mathrm{~N}\right), 68.4\left(\mathrm{CCH}_{2} \mathrm{O}\right), 67.5\left(\mathrm{OCH}_{2} \mathrm{CH}_{2} \mathrm{~N}\right)$, $63.6\left(\mathrm{OCH}_{2} \mathrm{C}_{\text {triazole }}\right), 60.7$ (C-6), $55.3(\mathrm{C}-2), 50.0\left(\mathrm{OCH}_{2} \mathrm{CH}_{2} \mathrm{~N}, \mathrm{O}_{\text {linker }} \mathrm{CH}_{2} \mathrm{CH}_{2} \mathrm{~N}\right), 44.8$ $\left(\mathrm{CCH}_{2} \mathrm{O}\right), 43.2\left(\mathrm{CH}_{2} \mathrm{Cl}\right), 22.2\left(\mathrm{CH}_{3}\right.$ of NHAc); ESI-MS $\mathrm{m} / z$ calcd. for $\mathrm{C}_{166} \mathrm{H}_{270} \mathrm{ClN}_{45} \mathrm{O}_{76}$ : 4144.8; found: $2093.9[\mathrm{M}+2 \mathrm{Na}]^{+2}, 1404.4[\mathrm{M}+3 \mathrm{Na}]^{+3}, 1057.4[\mathrm{M}+2 \mathrm{Na}+\mathrm{K}+\mathrm{H}]^{+4}$.

\section{Glycodendron 15.}

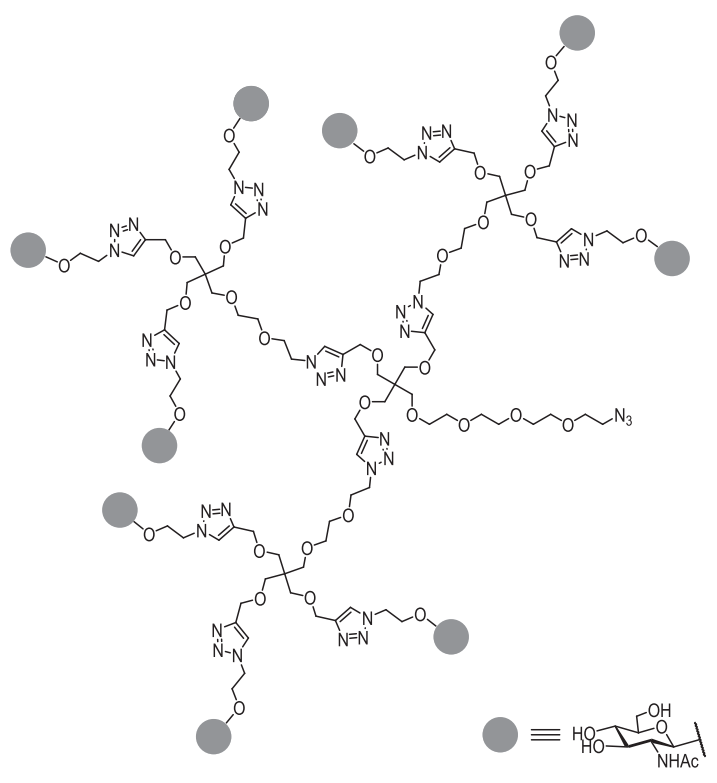

To a solution of glycodendron $14(242 \mathrm{mg}, 58.39 \mu \mathrm{mol})$ in DMF $(10 \mathrm{~mL})$ was added sodium azide ( $38 \mathrm{mg}, 0.58 \mathrm{mmol}$ ). The mixture was stirred at $60^{\circ} \mathrm{C}$ for 3 days. After that time, the solvent was concentrated and the crude was purified by size-exclusion chromatography (Sephadex G-25, $\mathrm{H}_{2} \mathrm{O} / \mathrm{MeOH}$ 9/1), furnishing the glycodendron 15 (237 mg, $57.08 \mu \mathrm{mol}, 98 \%$ ) as a white amorphous solid. ${ }^{1} \mathrm{H}-\mathrm{NMR}\left(400 \mathrm{MHz}, \mathrm{D}_{2} \mathrm{O}\right) 7.97$ (s, $\left.3 \mathrm{H}, \mathrm{H}_{\text {triazole }}\right), 7.94$ (s, 9H, $\left.\mathrm{H}_{\text {triazole }}\right), 4.63-4.51\left(\mathrm{~m}, 42 \mathrm{H}, \mathrm{OCH}_{2} \mathrm{CH}_{2} \mathrm{~N}, \mathrm{O}_{\text {linker }} \mathrm{CH}_{2} \mathrm{CH}_{2} \mathrm{~N}\right.$, $\mathrm{OCH}_{2} \mathrm{C}_{\text {triazole }}$ ), 4.48 (br s, $6 \mathrm{H}, \mathrm{OCH}_{2} \mathrm{C}_{\text {triazole }}$ ), 4.45 (d, 9H, $\left.J_{1,2}=8.4, \mathrm{H}-1\right), 4.28$ (m, 9H, $\left.\mathrm{OCHHCH}_{2} \mathrm{~N}\right), 4.01\left(\mathrm{~m}, 9 \mathrm{H}, \mathrm{OCH} \mathrm{CH}_{2} \mathrm{~N}\right), 3.95-3.85\left(\mathrm{~m}, 15 \mathrm{H}, \mathrm{O}_{\text {linker }} \mathrm{CH}_{2} \mathrm{CH}_{2} \mathrm{~N}, \mathrm{H}-6 \mathrm{a}\right)$, $3.73\left(\mathrm{dd}, 9 \mathrm{H}, J_{6 \mathrm{~b}, 6 \mathrm{a}}=12.2, J_{6 \mathrm{~b}, 5}=5.3, \mathrm{H}-6 \mathrm{~b}\right), 3.68-3.58\left(\mathrm{~m}, 19 \mathrm{H}, \mathrm{H}-2, \mathrm{CH}_{2} \mathrm{CH}_{2} \mathrm{~N}_{3}, \mathrm{CH}_{2} \mathrm{O}\right)$, 3.57-3.36 (m, 69H, H-3, H-4, H-5, $\left.\mathrm{CH}_{2} \mathrm{~N}_{3}, \mathrm{CCH}_{2} \mathrm{O}, \mathrm{CH}_{2} \mathrm{O}\right), 3.33(\mathrm{~m}, 8 \mathrm{H}$, $\mathrm{CCH}_{2} \mathrm{OCH}_{2} \mathrm{CH}_{2} \mathrm{O}$ ), 1.85 (s, 27H, $\mathrm{CH}_{3}$ of NHAc); ${ }^{13} \mathrm{C}-\mathrm{NMR}\left(100 \mathrm{MHz}, \mathrm{D}_{2} \mathrm{O}\right) 173.9$ (CO), 144.1 ( $\left.\mathrm{C}_{\text {triazole }}\right), 144.0\left(\mathrm{C}_{\text {triazole }}\right), 125.2\left(\mathrm{CH}_{\text {triazole }}\right), 125.1\left(\mathrm{CH}_{\text {triazole }}\right), 100.9(\mathrm{C}-1), 75.9(\mathrm{C}-$ 5), $73.6(\mathrm{C}-3), 70.5,70.4\left(\mathrm{CH}_{2} \mathrm{O}\right), 69.9(\mathrm{C}-4), 69.7\left(\mathrm{CH}_{2} \mathrm{O}\right), 69.6\left(\mathrm{CH}_{2} \mathrm{O}\right), 69.2$ $\left(\mathrm{CH}_{2} \mathrm{CH}_{2} \mathrm{~N}_{3}\right), 69.0\left(\mathrm{CCH}_{2} \mathrm{OCH}_{2} \mathrm{CH}_{2} \mathrm{O}\right), 68.7\left(\mathrm{O}_{\text {linker }} \mathrm{CH}_{2} \mathrm{CH}_{2} \mathrm{~N}\right), 68.4\left(\mathrm{CCH}_{2} \mathrm{O}\right), 67.5$ $\left(\mathrm{OCH}_{2} \mathrm{CH}_{2} \mathrm{~N}\right), 63.6\left(\mathrm{OCH}_{2} \mathrm{C}_{\text {triazole }}\right), 60.7(\mathrm{C}-6), 55.3(\mathrm{C}-2), 50.1 \quad\left(\mathrm{CH}_{2} \mathrm{~N}_{3}\right), \quad 50.0$ $\left(\mathrm{OCH}_{2} \mathrm{CH}_{2} \mathrm{~N}, \mathrm{O}_{\text {linker }} \mathrm{CH}_{2} \mathrm{CH}_{2} \mathrm{~N}\right), 44.8\left(\mathrm{CCH}_{2} \mathrm{O}\right), 22.2\left(\mathrm{CH}_{3}\right.$ of $\left.\mathrm{NHAc}\right)$; ESI-MS $\mathrm{m} / z$ calcd. 
for $\mathrm{C}_{166} \mathrm{H}_{270} \mathrm{~N}_{48} \mathrm{O}_{76}$ : 4151.9; found: $2097.7[\mathrm{M}+2 \mathrm{Na}]^{+2}, 1406.6[\mathrm{M}+3 \mathrm{Na}]^{+3}, 1061.0$ $[\mathrm{M}+4 \mathrm{Na}]^{+4}$.

\section{Glycodendron 3.}

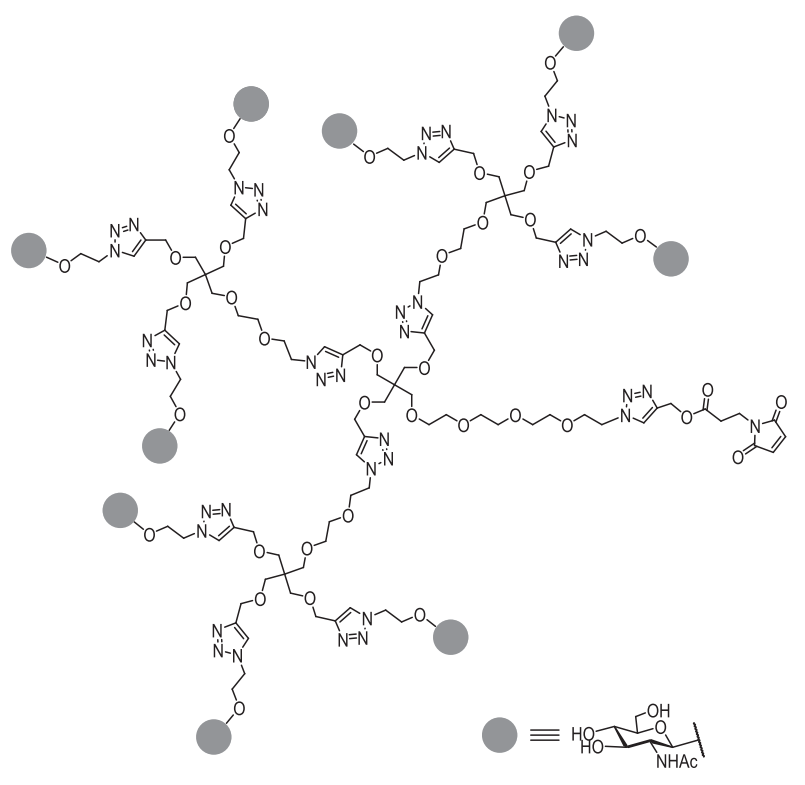

To a solution of glycodendron $15(25 \mathrm{mg}, 6.02 \mu \mathrm{mol})$ in $\mathrm{H}_{2} \mathrm{O} / \mathrm{DMSO}(300 \mu \mathrm{L}, 2: 1)$, a solution of maleimido derivative $16[\mathrm{iv}](1.87 \mathrm{mg}, 9.03 \mu \mathrm{mol})$ in DMSO $(100 \mu \mathrm{L})$ was added. Subsequently, solution of $\mathrm{CuBr}(1.73 \mathrm{mg}, 12.04 \mu \mathrm{mol})$ and TBTA $(6.25 \mathrm{mg}, 12.04$ $\mu \mathrm{mol})$ in DMSO $(200 \mu \mathrm{L})$ was added to the former solution. After shaking for aprox. 50 min at room temperature, the reaction mixture was directly purified by semipreparative RP-HPLC (column $\mathrm{C}_{8}$ and the elution with a linear gradient from 12 to $22 \%$ of solvent $\mathrm{B}$ into A over $40 \mathrm{~min}$, at $3 \mathrm{~mL} / \mathrm{min}$ flow rate (A: $\mathrm{H}_{2} \mathrm{O}(0.05 \%$ TFA), B: ACN (0.1\% TFA)) to give the target compound $3(5.1 \mathrm{mg}, 1.17 \mu \mathrm{mol}, 20 \%)$ as a white solid. MALDI-ToF MS $m / z$ calcd. for $\mathrm{C}_{176} \mathrm{H}_{279} \mathrm{~N}_{49} \mathrm{O}_{80}$ : 4358.9; found: $4358.3[\mathrm{M}]^{+} ; \mathrm{HPLC} \mathrm{t}_{\mathrm{R}}=5.44 \mathrm{~min}$ (Column: analytical $\mathrm{C}_{8}$; A: $\mathrm{H}_{2} \mathrm{O}(0.05 \%$ TFA), B: Acetonitrile (0.1 \% TFA), 15 to $35 \%$ linear gradient of B into A over $15 \mathrm{~min}, \mathrm{~F}=1 \mathrm{~mL} / \mathrm{min}$ ). Characterization data are shown in Figure S2 
A) HPLC chromatogram

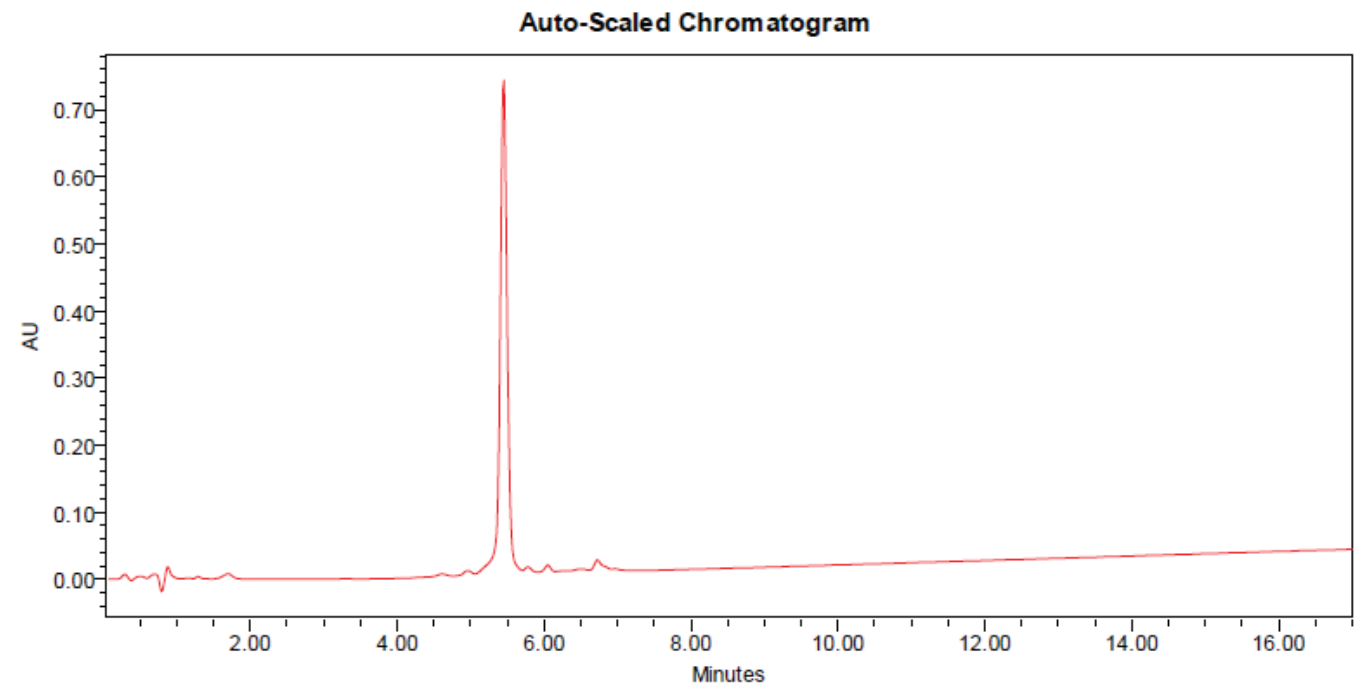

B) MALDI-ToF-MS

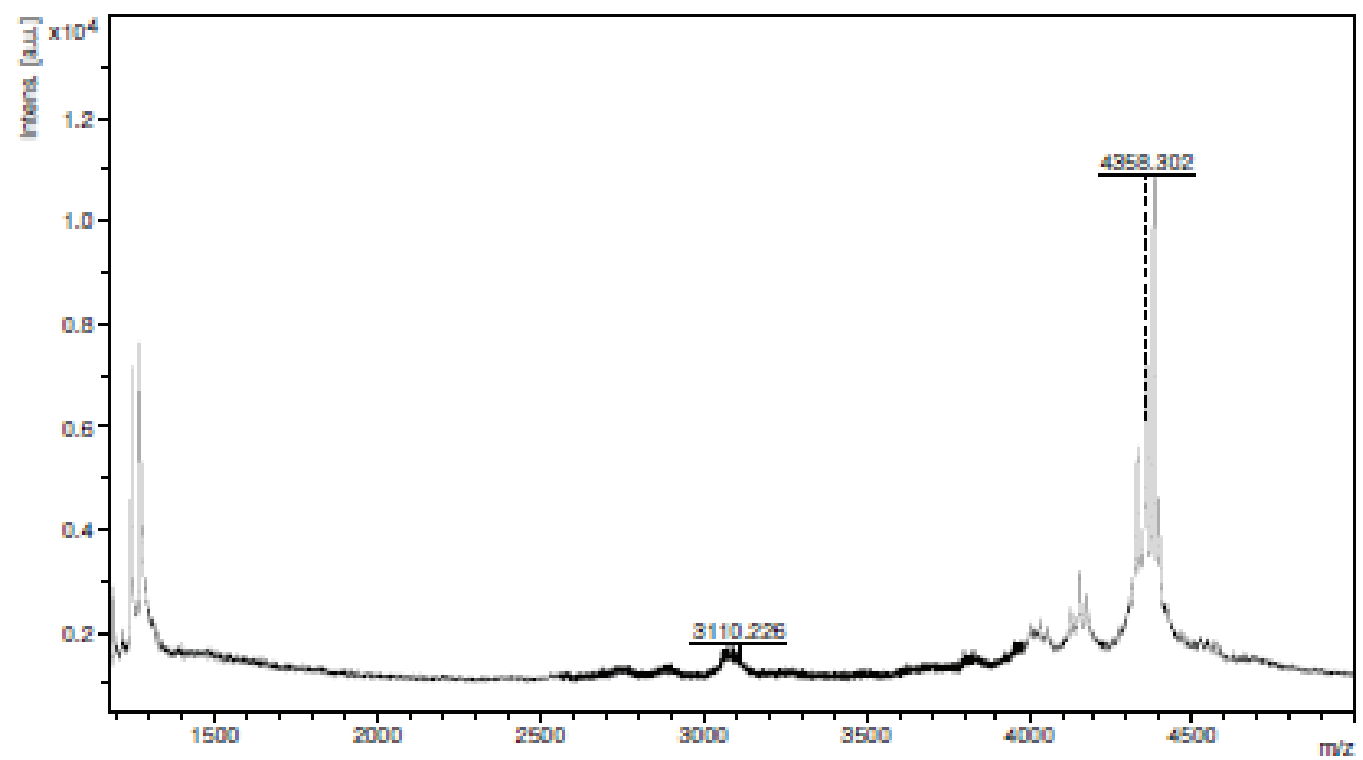

Figure S2. A) HPLC of the click reaction for obtaining compound $\mathbf{3}$ after HPLC purification. B) MALDI-ToF-MS for compound 17: MW calculated 4358.9 (M+) Dalton; Found 4358.3 Dalton (M+). 
Synthesis and Characterization of dendropeptide $\mathrm{D}_{1} \mathrm{OE}$ (D4) and the corresponding synthetic intermediates
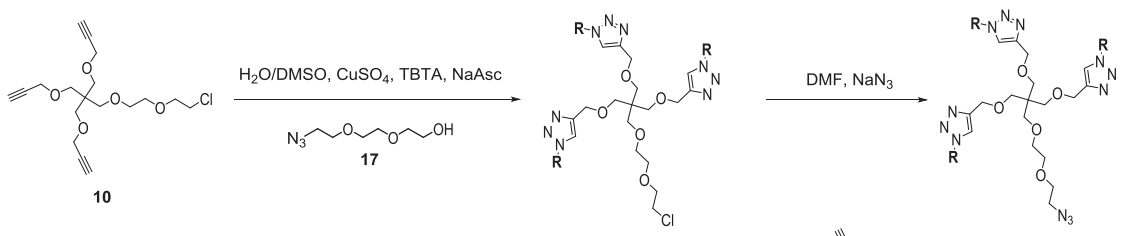

$\mathrm{R}=\widehat{\mathrm{O} \sim \mathrm{O}} \mathrm{\sim OH}$

18
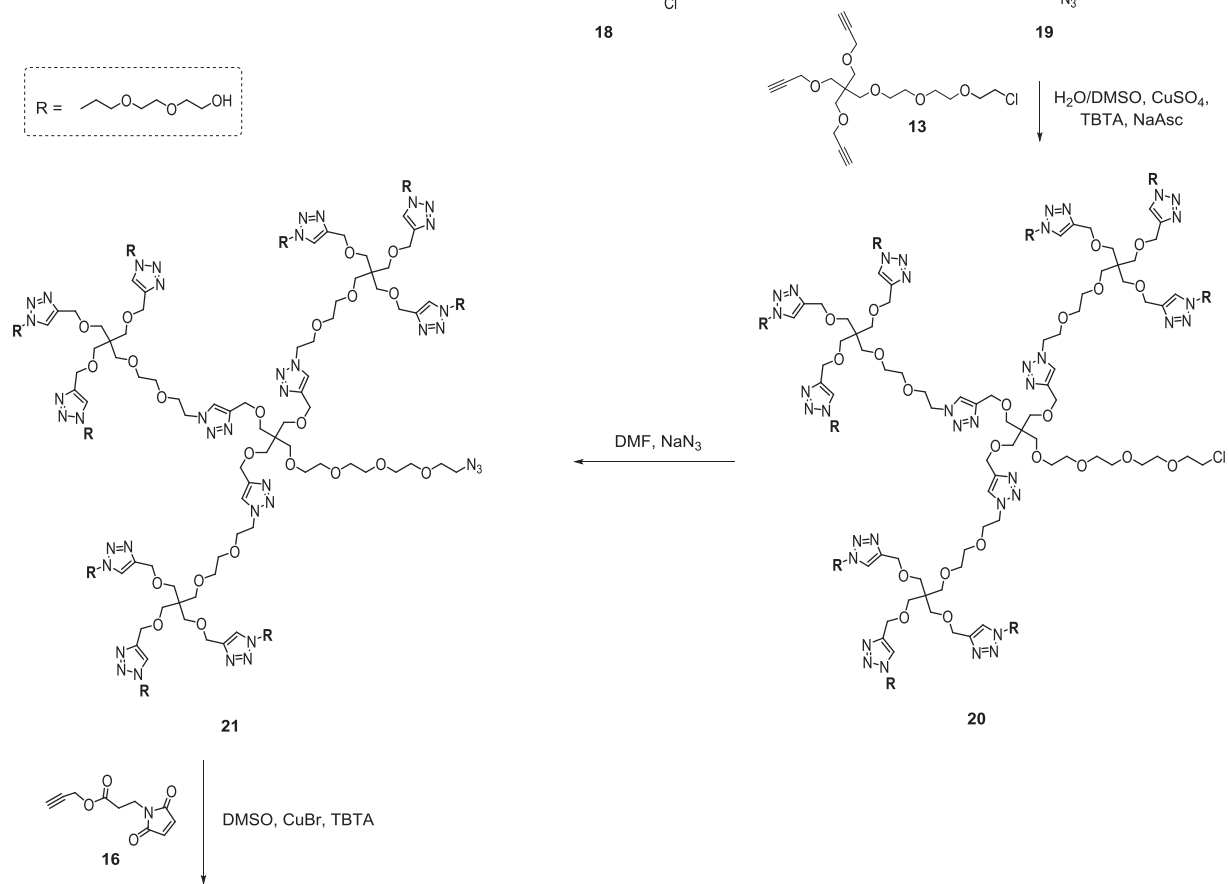

DMF, $\mathrm{NaN}_{3}$
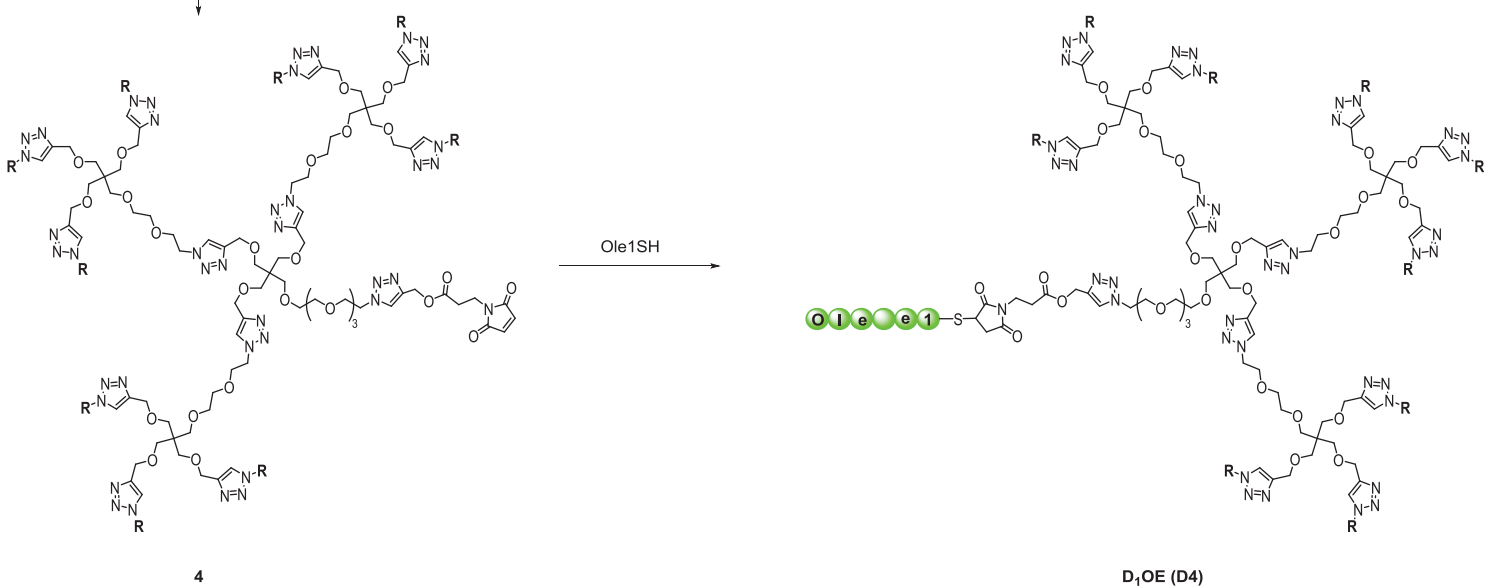

Figure S3. Synthetic scheme for the preparation of dendropeptide $\mathrm{D}_{1} \mathrm{OE}$ (D4). 


\section{Dendron 18.}

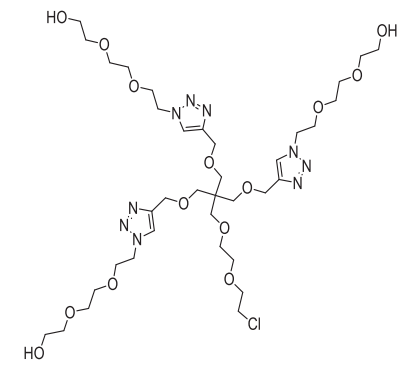

2-[2-(2-azidoethoxy)ethoxy] ethanol $\mathbf{1 7}^{1}$ (708 mg, $4.04 \mathrm{mmol}$ ), compound $\mathbf{1 0}^{2}$ (400 $\mathrm{mg}$, $1.12 \mathrm{mmol}$ ), $\mathrm{CuSO}_{4} \cdot 5 \mathrm{H}_{2} \mathrm{O}(57 \mathrm{mg}, 0.22 \mathrm{mmol}$ ), TBTA (246 mg, $0.45 \mathrm{mmol}$ ) and sodium ascorbate $(136 \mathrm{mg}, 0.68 \mathrm{mmol})$ were dissolved in $\mathrm{H}_{2} \mathrm{O} / \mathrm{DMSO}(1: 1,3 \mathrm{~mL})$ in a sealed microwaves vial. The solution was heated at $60^{\circ} \mathrm{C}$ in a microwaves oven for $30 \mathrm{~min}$. A metal scavenger resin, QuadrasilMP, was added to the reaction solution and stirred for 5 min at room temperature. After that, the mixture was filtered and the resulting solution was purified by silica gel column chromatography $\left(\mathrm{CH}_{2} \mathrm{Cl}_{2} / \mathrm{MeOH}, 20: 1 \rightarrow 10: 1\right)$, furnishing the dendron 18 (792 $\mathrm{mg}, 0.90 \mathrm{mmol}, 80 \%)$ as a yellow oil. ${ }^{1} \mathrm{H}-\mathrm{NMR}$ (400 $\left.\mathrm{MHz}_{\mathrm{CDCl}}\right) 7.78$ (s, 3H, $\left.\mathrm{H}_{\text {triazole }}\right), 4.55\left(\mathrm{~s}, 6 \mathrm{H}, \mathrm{OCH}_{2} \mathrm{C}_{\text {triazole }}\right), 4.52$ (t, $6 \mathrm{H}, J_{\mathrm{H}, \mathrm{H}}=4.9$, $\left.\mathrm{OCH}_{2} \mathrm{CH}_{2} \mathrm{~N}\right), 3.86\left(\mathrm{t}, 6 \mathrm{H}, J_{\mathrm{H}, \mathrm{H}}=4.9, \mathrm{OCH}_{2} \mathrm{CH}_{2} \mathrm{~N}\right), 3.74-3.66\left(\mathrm{~m}, 8 \mathrm{H}, \mathrm{OCH}_{2} \mathrm{CH}_{2} \mathrm{OH}\right.$, $\mathrm{OCH}_{2} \mathrm{CH}_{2} \mathrm{Cl}$ ), 3.63-3.56 (m, $16 \mathrm{H}, \mathrm{OCH}_{2} \mathrm{CH}_{2} \mathrm{Cl}, \mathrm{CCH}_{2} \mathrm{OCH}_{2} \mathrm{CH}_{2} \mathrm{O}, \mathrm{CH}_{2} \mathrm{O}$ ), 3.56-3.50 (m, $\left.8 \mathrm{H}, \mathrm{OCH}_{2} \mathrm{CH}_{2} \mathrm{OH}, \mathrm{CCH}_{2} \mathrm{OCH}_{2} \mathrm{CH}_{2} \mathrm{O}\right), 3.46\left(\mathrm{~s}, 6 \mathrm{H}, \mathrm{CCH}_{2} \mathrm{O}\right), 3.42(\mathrm{~s}, 2 \mathrm{H}$, $\mathrm{CCH}_{2} \mathrm{OCH}_{2} \mathrm{CH}_{2} \mathrm{O}$ ), 3.16 (br s, 3H, OH); ${ }^{13} \mathrm{C}-\mathrm{NMR}\left(100 \mathrm{MHz}, \mathrm{CDCl}_{3}\right) 144.1\left(\mathrm{C}_{\text {triazole }}\right)$, $123.2\left(\mathrm{CH}_{\text {triazole }}\right), 71.8\left(\mathrm{OCH}_{2} \mathrm{CH}_{2} \mathrm{OH}\right), 70.3\left(\mathrm{OCH}_{2} \mathrm{CH}_{2} \mathrm{Cl}\right), 70.1\left(\mathrm{CCH}_{2} \mathrm{OCH}_{2} \mathrm{CH}_{2} \mathrm{O}\right)$, 69.5 $\left(\mathrm{CH}_{2} \mathrm{O}\right), 69.4\left(\mathrm{CH}_{2} \mathrm{O}\right), 68.9\left(\mathrm{CCH}_{2} \mathrm{OCH}_{2} \mathrm{CH}_{2} \mathrm{O}\right), 68.5\left(\mathrm{OCH}_{2} \mathrm{CH}_{2} \mathrm{~N}\right), 68.3\left(\mathrm{CCH}_{2} \mathrm{O}\right)$, $63.9\left(\mathrm{OCH}_{2} \mathrm{C}_{\text {triazole }}\right), 60.4\left(\mathrm{OCH}_{2} \mathrm{CH}_{2} \mathrm{OH}\right), 49.2\left(\mathrm{OCH}_{2} \mathrm{CH}_{2} \mathrm{~N}\right), 44.5\left(\mathrm{CCH}_{2} \mathrm{O}\right), 42.4$ $\left(\mathrm{OCH}_{2} \mathrm{CH}_{2} \mathrm{Cl}\right)$; ESI-MS m/z calcd. for $\mathrm{C}_{36} \mathrm{H}_{64} \mathrm{ClN}_{9} \mathrm{O}_{14}$ : 881.4; found: $904.6[\mathrm{M}+\mathrm{Na}]^{+}$; FAB-HRMS $m / z$ calcd. for $\mathrm{C}_{36} \mathrm{H}_{64} \mathrm{ClN}_{9} \mathrm{O}_{14} \mathrm{Na}[\mathrm{M}+\mathrm{Na}]^{+}$: 904.4159 ; found: 904.4164 . 


\section{Dendron 19.}

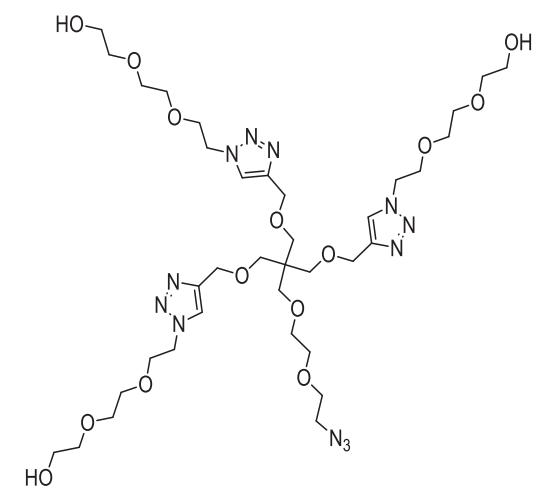

To a solution of dendron 18 (750 $\mathrm{mg}, 0.85 \mathrm{mmol})$ in DMF $(15 \mathrm{~mL})$ was added sodium azide $(553 \mathrm{mg}, 8.51 \mathrm{mmol})$. The mixture was stirred at $60^{\circ} \mathrm{C}$ for 3 days. After that time, the solvent was concentrated and the crude was purified by size-exclusion chromatography (Sephadex LH-20, $\mathrm{MeOH} / \mathrm{CH}_{2} \mathrm{Cl}_{2}$ 1:1), to give the azide dendron 19 (755 mg, $0.85 \mathrm{mmol}$, quant.) as a colourless oil. ${ }^{1} \mathrm{H}-\mathrm{NMR}\left(400 \mathrm{MHz}, \mathrm{CDCl}_{3}\right) 7.77$ (s, 3H, $\left.\mathrm{H}_{\text {triazole }}\right), 4.55\left(\mathrm{~s}, 6 \mathrm{H}, \mathrm{OCH}_{2} \mathrm{C}_{\text {triazole }}\right), 4.52\left(\mathrm{t}, 6 \mathrm{H}, J_{\mathrm{H}, \mathrm{H}}=4.9, \mathrm{OCH}_{2} \mathrm{CH}_{2} \mathrm{~N}\right), 3.86\left(\mathrm{t}, 6 \mathrm{H}, J_{\mathrm{H}, \mathrm{H}}\right.$ $\left.=4.9, \mathrm{OCH}_{2} \mathrm{CH}_{2} \mathrm{~N}\right), 3.69\left(\mathrm{~m}, 6 \mathrm{H}, \mathrm{OCH}_{2} \mathrm{CH}_{2} \mathrm{OH}\right), 3.63\left(\mathrm{t}, 2 \mathrm{H}, J_{\mathrm{H}, \mathrm{H}}=4.9, \mathrm{OCH}_{2} \mathrm{CH}_{2} \mathrm{~N}_{3}\right)$, 3.61-3.56 (m, $\left.14 \mathrm{H}, \mathrm{CCH}_{2} \mathrm{OCH}_{2} \mathrm{CH}_{2} \mathrm{O}, \mathrm{CH}_{2} \mathrm{O}\right), 3.56-3.50\left(\mathrm{~m}, 8 \mathrm{H}, \mathrm{OCH}_{2} \mathrm{CH}_{2} \mathrm{OH}\right.$, $\mathrm{CCH}_{2} \mathrm{OCH}_{2} \mathrm{CH}_{2} \mathrm{O}$ ), 3.46 (s, 6H, $\mathrm{CCH}_{2} \mathrm{O}$ ), 3.42 (s, 2H, $\left.\mathrm{CCH}_{2} \mathrm{OCH}_{2} \mathrm{CH}_{2} \mathrm{O}\right), 3.34$ (t, $2 \mathrm{H}$, $J_{\mathrm{H}, \mathrm{H}}=4.9, \mathrm{OCH}_{2} \mathrm{CH}_{2} \mathrm{~N}_{3}$ ), 3.09 (br s, 3H, OH); ${ }^{13} \mathrm{C}-\mathrm{NMR}\left(100 \mathrm{MHz}, \mathrm{CDCl}_{3}\right) 144.4$ ( $\left.\mathrm{C}_{\text {triazole }}\right), 123.3\left(\mathrm{CH}_{\text {triazole }}\right), 72.0\left(\mathrm{OCH}_{2} \mathrm{CH}_{2} \mathrm{OH}\right), 70.4\left(\mathrm{CCH}_{2} \mathrm{OCH}_{2} \mathrm{CH}_{2} \mathrm{O}\right), 69.8\left(\mathrm{CH}_{2} \mathrm{O}\right)$, $69.7\left(\mathrm{CCH}_{2} \mathrm{OCH}_{2} \mathrm{CH}_{2} \mathrm{O}\right), 69.6\left(\mathrm{CH}_{2} \mathrm{O}\right), 69.3\left(\mathrm{OCH}_{2} \mathrm{CH}_{2} \mathrm{~N}_{3}\right), 69.2\left(\mathrm{CCH}_{2} \mathrm{OCH}_{2} \mathrm{CH}_{2} \mathrm{O}\right)$, $68.7\left(\mathrm{OCH}_{2} \mathrm{CH}_{2} \mathrm{~N}\right), 68.6\left(\mathrm{CCH}_{2} \mathrm{O}\right), 64.2\left(\mathrm{OCH}_{2} \mathrm{C}_{\text {triazole }}\right), 60.7\left(\mathrm{OCH}_{2} \mathrm{CH}_{2} \mathrm{OH}\right), 50.1$ $\left(\mathrm{OCH}_{2} \mathrm{CH}_{2} \mathrm{~N}_{3}\right), 49.5\left(\mathrm{OCH}_{2} \mathrm{CH}_{2} \mathrm{~N}\right), 44.8\left(\mathrm{CCH}_{2} \mathrm{O}\right)$; ESI-MS $m / z$ calcd. for $\mathrm{C}_{36} \mathrm{H}_{64} \mathrm{~N}_{12} \mathrm{O}_{14}$ : 888.5; found: $911.6[\mathrm{M}+\mathrm{Na}]^{+}, 467.3[\mathrm{M}+2 \mathrm{Na}]^{2+}$; FAB-HRMS $m / z$ calcd. for $\mathrm{C}_{36} \mathrm{H}_{64} \mathrm{~N}_{12} \mathrm{O}_{14} \mathrm{Na}[\mathrm{M}+\mathrm{Na}]^{+}$: 911.4557 ; found: 911.4563 . 


\section{Dendron 20.}

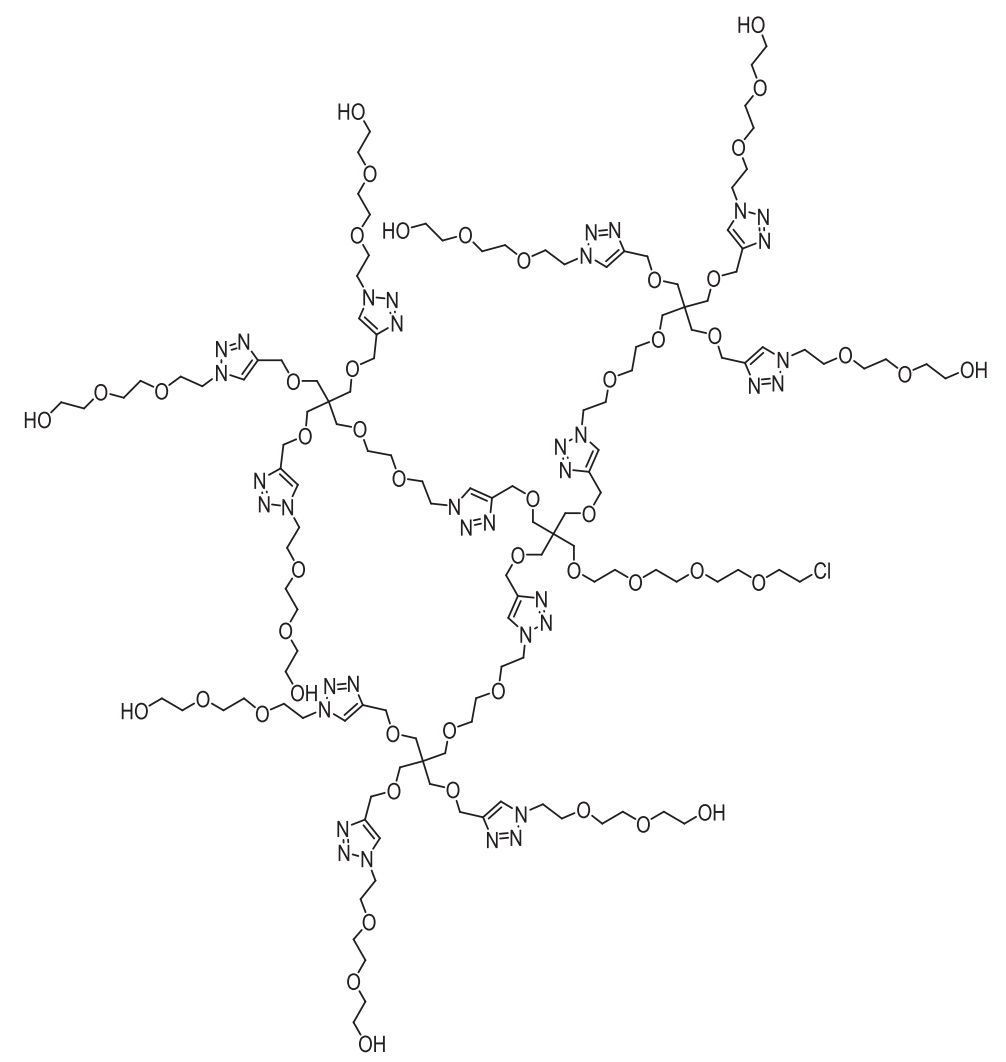

Dendron 19 (600 mg, $0.68 \mathrm{mmol}$ ), compound 13;Error! Marcador no definido. (83 mg, 0.19 $\mathrm{mmol}), \mathrm{CuSO}_{4} \cdot 5 \mathrm{H}_{2} \mathrm{O}(10 \mathrm{mg}, 0.04 \mathrm{mmol})$, TBTA (41 mg, $\left.0.08 \mathrm{mmol}\right)$ and sodium ascorbate $(23 \mathrm{mg}, 0.11 \mathrm{mmol})$ were dissolved in $\mathrm{H}_{2} \mathrm{O} / \mathrm{DMSO}(1: 1,4 \mathrm{~mL})$ in a sealed microwaves vial. The solution was heated at $60^{\circ} \mathrm{C}$ in a microwaves oven for $30 \mathrm{~min}$. A metal scavenger resin, QuadrasilMP, was added to the reaction solution and stirred for 5 min at room temperature. After that, the mixture was filtered and the resulting solution was purified by size-exclusion chromatography (Sephadex LH-20, MeOH 100\%), furnishing the dendron 20 (490 mg, $0.16 \mathrm{mmol}, 84 \%$ ) as a colourless oil. ${ }^{1} \mathrm{H}-\mathrm{NMR}$ (400 $\left.\mathrm{MHz}, \mathrm{CD}_{3} \mathrm{OD}\right) 7.98\left(\mathrm{~s}, 9 \mathrm{H}, \mathrm{H}_{\text {triazole }}\right), 7.94\left(\mathrm{~s}, 3 \mathrm{H}, \mathrm{H}_{\text {triazole }}\right), 4.56\left(\mathrm{t}, 18 \mathrm{H}, J_{\mathrm{H}, \mathrm{H}}=5.0\right.$, $\left.\mathrm{OCH}_{2} \mathrm{CH}_{2} \mathrm{~N}\right), 4.53\left(\mathrm{~m}, 6 \mathrm{H}, \mathrm{O}_{\text {linker }} \mathrm{CH}_{2} \mathrm{CH}_{2} \mathrm{~N}\right), 4.51\left(\mathrm{~s}, 18 \mathrm{H}, \mathrm{OCH}_{2} \mathrm{C}_{\text {triazole }}\right), 4.50(\mathrm{~s}, 6 \mathrm{H}$, $\left.\mathrm{OCH}_{2} \mathrm{C}_{\text {triazole }}\right), 3.89\left(\mathrm{t}, 18 \mathrm{H}, J_{\mathrm{H}, \mathrm{H}}=5.0, \mathrm{OCH}_{2} \mathrm{CH}_{2} \mathrm{~N}\right), 3.86\left(\mathrm{~m}, 6 \mathrm{H}, \mathrm{O}_{\text {linker }} \mathrm{CH}_{2} \mathrm{CH}_{2} \mathrm{~N}\right), 3.70$ (m, $2 \mathrm{H}, \mathrm{OCH}_{2} \mathrm{CH}_{2} \mathrm{Cl}$ ), 3.66-3.55 (m, 64H, $\mathrm{OCH}_{2} \mathrm{CH}_{2} \mathrm{OH}, \mathrm{OCH}_{2} \mathrm{CH}_{2} \mathrm{Cl}, \mathrm{CH}_{2} \mathrm{O}$ ), 3.55$3.48\left(\mathrm{~m}, 28 \mathrm{H}, \mathrm{OCH}_{2} \mathrm{CH}_{2} \mathrm{OH}, \mathrm{CH}_{2} \mathrm{O}\right), 3.48-3.42\left(\mathrm{~m}, 30 \mathrm{H}, \mathrm{CCH}_{2} \mathrm{O}, \mathrm{CH}_{2} \mathrm{O}\right), 3.39$ (s, $2 \mathrm{H}$, $\mathrm{CCH}_{2} \mathrm{OCH}_{2} \mathrm{CH}_{2} \mathrm{O}$ ), 3.38 (s, 6H, $\left.\mathrm{CCH}_{2} \mathrm{OCH}_{2} \mathrm{CH}_{2} \mathrm{O}\right) ;{ }^{13} \mathrm{C}-\mathrm{NMR}\left(100 \mathrm{MHz}, \mathrm{CD}_{3} \mathrm{OD}\right)$ 145.9 ( $\left.\mathrm{C}_{\text {triazole }}\right), \quad 125.6$ ( $\left.\mathrm{CH}_{\text {triazole }}\right), 125.5\left(\mathrm{CH}_{\text {triazole }}\right), 73.6 \quad\left(\mathrm{OCH}_{2} \mathrm{CH}_{2} \mathrm{OH}\right), \quad 72.3$ $\left(\mathrm{OCH}_{2} \mathrm{CH}_{2} \mathrm{Cl}\right), 72.0\left(\mathrm{CH}_{2} \mathrm{O}\right), 71.5\left(\mathrm{CH}_{2} \mathrm{O}\right), 71.4\left(\mathrm{CH}_{2} \mathrm{O}\right), 71.3\left(\mathrm{CH}_{2} \mathrm{O}\right), 71.2\left(\mathrm{CH}_{2} \mathrm{O}\right), 71.1$ $\left(\mathrm{CH}_{2} \mathrm{O}\right), 70.7\left(\mathrm{CCH}_{2} \mathrm{OCH}_{2} \mathrm{CH}_{2} \mathrm{O}\right), 70.4\left(\mathrm{O}_{\text {linker }} \mathrm{CH}_{2} \mathrm{CH}_{2} \mathrm{~N}\right) 70.3\left(\mathrm{OCH}_{2} \mathrm{CH}_{2} \mathrm{~N}\right), 70.0$ $\left(\mathrm{CCH}_{2} \mathrm{O}\right), 65.3\left(\mathrm{OCH}_{2} \mathrm{C}_{\text {triazole }}\right), 62.1\left(\mathrm{OCH}_{2} \mathrm{CH}_{2} \mathrm{OH}\right), 51.3\left(\mathrm{O}_{\text {linker }} \mathrm{CH}_{2} \mathrm{CH}_{2} \mathrm{~N}\right), \quad 51.2$ $\left(\mathrm{OCH}_{2} \mathrm{CH}_{2} \mathrm{~N}\right), \quad 46.5 \quad\left(\mathrm{CCH}_{2} \mathrm{O}\right), \quad 44.0 \quad\left(\mathrm{OCH}_{2} \mathrm{CH}_{2} \mathrm{Cl}\right)$; ESI-MS $\mathrm{m} / \mathrm{z}$ calcd. for 
$\mathrm{C}_{130} \mathrm{H}_{225} \mathrm{ClN}_{36} \mathrm{O}_{49}: \quad 3111.8$; found: $3134.1[\mathrm{M}+\mathrm{Na}]^{+}, \quad 1578.9 \quad[\mathrm{M}+2 \mathrm{Na}]^{2+}, \quad 1059.5$ $[\mathrm{M}+3 \mathrm{Na}]^{3+}, 800.4[\mathrm{M}+4 \mathrm{Na}]^{4+}$.

\section{Dendron 21.}

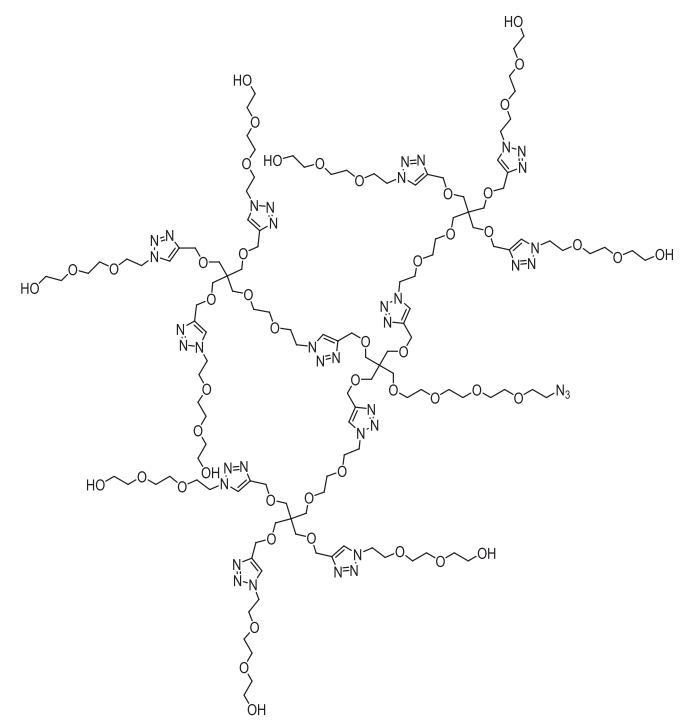

To a solution of dendron 20 (359 mg, $125 \square \mathrm{mol})$ in DMF (6 mL) was added sodium azide ( $82 \mathrm{mg}, 1.25 \mathrm{mmol})$. The mixture was stirred at $60^{\circ} \mathrm{C}$ for 3 days. After that time, the solvent was concentrated and the crude was purified by size-exclusion chromatography (Sephadex LH-20, MeOH 100\%), to give the azide dendron 21 (370 mg, $119 \square \mathrm{mol}, 95 \%$ ) as a colourless oil. ${ }^{1} \mathrm{H}-\mathrm{NMR}\left(400 \mathrm{MHz}, \mathrm{CD}_{3} \mathrm{OD}\right) 7.98$ (s, 9H, $\left.\mathrm{H}_{\text {triazole }}\right), 7.94$ (s, 3H, $\left.\mathrm{H}_{\text {triazole }}\right), 4.56\left(\mathrm{t}, 18 \mathrm{H}, J_{\mathrm{H}, \mathrm{H}}=5.1, \mathrm{OCH}_{2} \mathrm{CH}_{2} \mathrm{~N}\right), 4.53\left(\mathrm{~m}, 6 \mathrm{H}, \mathrm{O}_{\text {linker }} \mathrm{CH}_{2} \mathrm{CH}_{2} \mathrm{~N}\right), 4.51(\mathrm{~s}$, $\left.18 \mathrm{H}, \mathrm{OCH}_{2} \mathrm{C}_{\text {triazole }}\right), 4.49$ (s, $\left.6 \mathrm{H}, \mathrm{OCH}_{2} \mathrm{C}_{\text {triazole }}\right), 3.89$ (t, $18 \mathrm{H}, J_{\mathrm{H}, \mathrm{H}}=5.1, \mathrm{OCH}_{2} \mathrm{CH}_{2} \mathrm{~N}$ ), $3.86\left(\mathrm{~m}, 6 \mathrm{H}, \mathrm{O}_{\text {linker }} \mathrm{CH}_{2} \mathrm{CH}_{2} \mathrm{~N}\right), 3.66-3.56\left(\mathrm{~m}, 64 \mathrm{H}, \mathrm{OCH}_{2} \mathrm{CH}_{2} \mathrm{OH}, \mathrm{OCH}_{2} \mathrm{CH}_{2} \mathrm{~N}_{3}, \mathrm{CH}_{2} \mathrm{O}\right)$, 3.56-3.47 (m, 28H, $\mathrm{OCH}_{2} \mathrm{CH}_{2} \mathrm{OH}, \mathrm{CH}_{2} \mathrm{O}$ ), 3.47-3.41 (m, 30H, $\mathrm{CCH}_{2} \mathrm{O}, \mathrm{CH}_{2} \mathrm{O}$ ), 3.39 (s, $\left.2 \mathrm{H}, \mathrm{CCH}_{2} \mathrm{OCH}_{2} \mathrm{CH}_{2} \mathrm{O}\right), 3.38\left(\mathrm{~s}, 6 \mathrm{H}, \mathrm{CCH}_{2} \mathrm{OCH}_{2} \mathrm{CH}_{2} \mathrm{O}\right), 3.34\left(\mathrm{t}, 2 \mathrm{H}, J_{\mathrm{H}, \mathrm{H}}=5.0\right.$, $\left.\mathrm{OCH}_{2} \mathrm{CH}_{2} \mathrm{~N}_{3}\right) ;{ }^{13} \mathrm{C}-\mathrm{NMR}\left(100 \mathrm{MHz}, \mathrm{CD}_{3} \mathrm{OD}\right) 145.9$ ( $\left.\mathrm{C}_{\text {triazole }}\right), 125.6\left(\mathrm{CH}_{\text {triazole }}\right), 125.5$ $\left(\mathrm{CH}_{\text {triazole }}\right), 73.5\left(\mathrm{OCH}_{2} \mathrm{CH}_{2} \mathrm{OH}\right), 72.0\left(\mathrm{CH}_{2} \mathrm{O}\right), 71.5\left(\mathrm{CH}_{2} \mathrm{O}\right), 71.4\left(\mathrm{CH}_{2} \mathrm{O}\right), 71.3\left(\mathrm{CH}_{2} \mathrm{O}\right)$, $71.2\left(\mathrm{CH}_{2} \mathrm{O}\right), 71.1\left(\mathrm{CH}_{2} \mathrm{O}\right), 70.9\left(\mathrm{OCH}_{2} \mathrm{CH}_{2} \mathrm{~N}_{3}\right), 70.6 \quad\left(\mathrm{CCH}_{2} \mathrm{OCH}_{2} \mathrm{CH}_{2} \mathrm{O}\right), 70.3$ $\left(\mathrm{O}_{\text {linker }} \mathrm{CH}_{2} \mathrm{CH}_{2} \mathrm{~N}\right) \quad 70.2\left(\mathrm{OCH}_{2} \mathrm{CH}_{2} \mathrm{~N}\right), \quad 70.0 \quad\left(\mathrm{CCH}_{2} \mathrm{O}\right), 65.3 \quad\left(\mathrm{OCH}_{2} \mathrm{C}_{\text {triazole }}\right), \quad 62.0$ $\left(\mathrm{OCH}_{2} \mathrm{CH}_{2} \mathrm{OH}\right), 51.6\left(\mathrm{OCH}_{2} \mathrm{CH}_{2} \mathrm{~N}_{3}\right), 51.3\left(\mathrm{O}_{\text {linker }} \mathrm{CH}_{2} \mathrm{CH}_{2} \mathrm{~N}\right), 51.2\left(\mathrm{OCH}_{2} \mathrm{CH}_{2} \mathrm{~N}\right), 46.4$ $\left(\mathrm{CCH}_{2} \mathrm{O}\right)$; ESI-MS $\mathrm{m} / \mathrm{z}$ calcd. for $\mathrm{C}_{130} \mathrm{H}_{225} \mathrm{~N}_{39} \mathrm{O}_{49}$ : 3118.4; found: $3141.5[\mathrm{M}+\mathrm{Na}]^{+}$, $1582.5[\mathrm{M}+2 \mathrm{Na}]^{2+}, 1062.6[\mathrm{M}+3 \mathrm{Na}]^{3+}$. 


\section{Dendron 4}

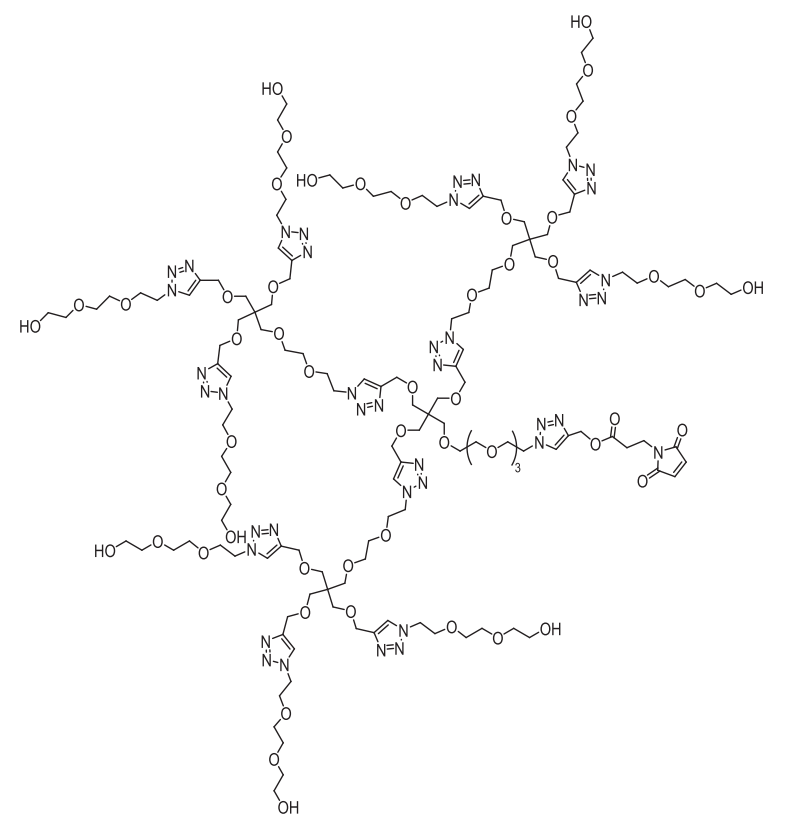

To a solution of maleimido derivative $16(2.4 \mathrm{mg}, 11.00 \mu \mathrm{mol})$ in DMSO $(235 \mu \mathrm{L})$, another solution of $\mathrm{CuBr}(1.1 \mathrm{mg}, 7.69 \mu \mathrm{mol})$ in the same solvent $(116 \mu \mathrm{L})$ was added. Subsequently, a solution of the triethylene glycol dendron $21(24 \mathrm{mg}, 7.69 \mu \mathrm{mol})$ in sodium phosphate buffer $(16 \mathrm{mM}$, pH 7.4, $351 \mu \mathrm{L})$ was added to the former solution. After shaking for aprox. $30 \mathrm{~min}$ at room temperature, the reaction mixture was directly purified by semipreparative RP-HPLC (column $\mathrm{C}_{18}$ and the elution with a linear gradient from 12 to $50 \%$ of solvent $\mathrm{B}$ into A over $30 \mathrm{~min}$, at $3 \mathrm{~mL} / \mathrm{min}$ flow rate $\left(\mathrm{A}: \mathrm{H}_{2} \mathrm{O}(0.05 \%\right.$ TFA), B: ACN (0.1\% TFA)) to give the target compound 4 (19.2 mg, $5.77 \mu \mathrm{mol}, 75 \%)$ as a colourless oil.

ESI-MS $\mathrm{m} / z$ calcd. for $\mathrm{C}_{140} \mathrm{H}_{23} \mathrm{~N}_{40} \mathrm{O}_{53}: 3324.7$; found: $3347.7[\mathrm{M}+\mathrm{Na}]^{+}, 1684.2$ $[\mathrm{M}+2 \mathrm{Na}]^{2+}, 1130.9[\mathrm{M}+3 \mathrm{Na}]^{3+} ; \mathrm{HPLC} \mathrm{t}_{\mathrm{R}}=6.5 \mathrm{~min}$ (Column: analytical $\mathrm{C}_{18} ; \mathrm{A}: \mathrm{H}_{2} \mathrm{O}$ (0.05\% TFA), B: Acetonitrile (0.1 \% TFA), 12 to $50 \%$ linear gradient of B into A over $15 \mathrm{~min}, \mathrm{~F}=1 \mathrm{~mL} / \mathrm{min})$. 


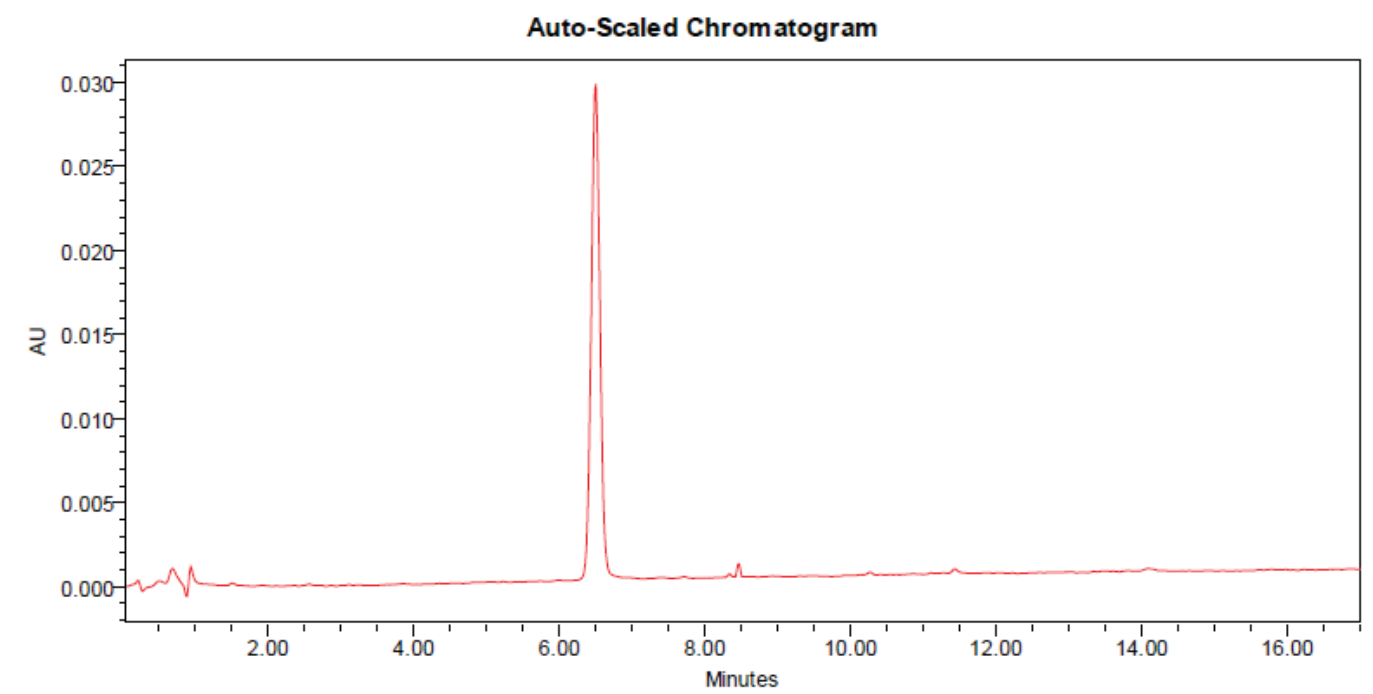

\section{B) ESI-MS}

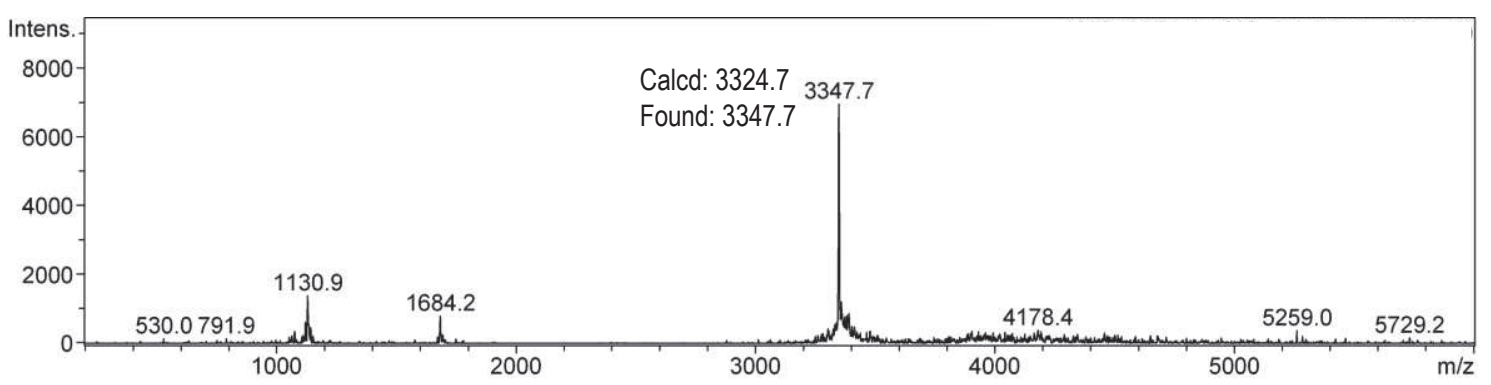

Figure S4. A) HPLC monitoring of the thiol-ene reaction for obtaining compound 4 and the peak corresponding to the same compound after HPLC purification (left). B) ESI-MS for compound 4: MW calculated 3324.7 $(\mathrm{M}+)$ Dalton; Found 3347.7 Dalton $(\mathrm{M}+\mathrm{Na})^{+}$, 1684.2 Dalton $(\mathrm{M}+2 \mathrm{Na})^{2+}, 1130.9$ Dalton $(\mathrm{M}+3 \mathrm{Na})^{3+}$.

\section{General protocol for the preparation of GDPs.}

A solution of peptide Ole ${ }_{109-130} \mathrm{SH}\left(1.1\right.$ eq.) in $\mathrm{H}_{2} \mathrm{O}$ MQ $(500 \mu \mathrm{L})$ was added to a solution of glyco-maleimide dendron 1-4 $\left(0.80 \mu \mathrm{mol}, 1\right.$ eq.) in $\mathrm{H}_{2} \mathrm{O} \mathrm{MQ}(500 \mu \mathrm{L})$ and sodium phosphate buffer $(50 \mathrm{mM}, \mathrm{pH} 7.4,500 \mu \mathrm{L})$. After shaking for aprox. $30 \mathrm{~min}$ at room temperature (the progression of the reaction was monitored by analytical RP-HPLC), the reaction mixture was lyophilized, and then purified by semipreparative RP-HPLC to give target compounds. 

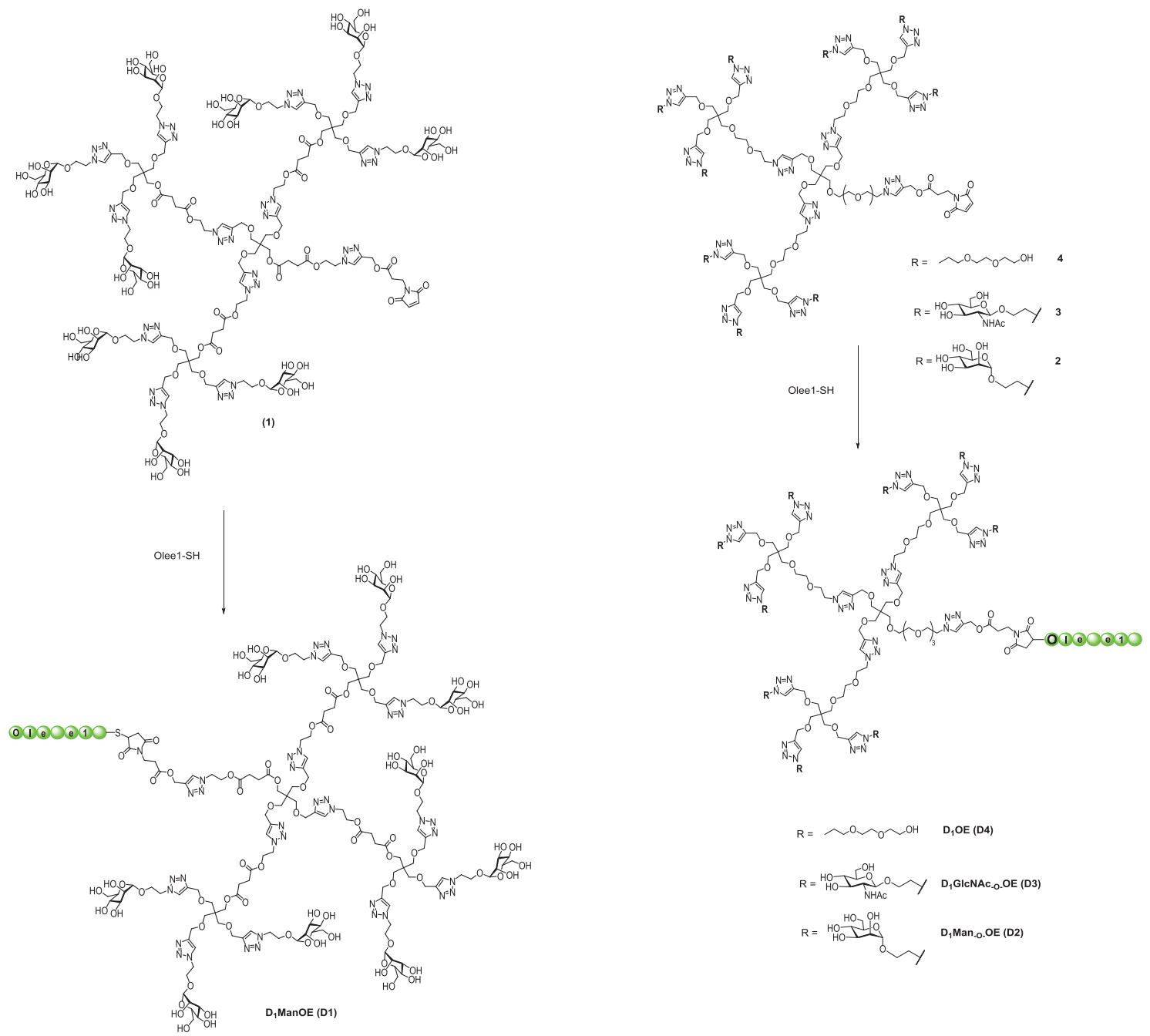

Figure S5. Conjugation of Olee1-SH to maleimide scaffolds 1-4 to obtain the conjugates D 1 ManOE (D1), D 1 Man-o-OE (D2), D ${ }_{1}$ GlcNAc-o-OE (D3), D1OE (D4).

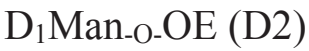

Following the general procedure, using glycodendron $\mathbf{2}$ as starting material, and purification by semipreparative RP-HPLC (column $\mathrm{C}_{18}$ and elution with a linear gradient from 15 to $35 \%$ of solvent $B$ into A over $30 \mathrm{~min}$, at $3 \mathrm{~mL} / \mathrm{min}$ flow rate $\left(\mathrm{A}: \mathrm{H}_{2} \mathrm{O}(0.05 \%\right.$ TFA), B: ACN (0.1\% TFA)), compound D1Man-o-OE (D2) (2.2 mg, $0.34 \mu \mathrm{mol}, 42 \%)$ was obtained as a white solid.

ESI-MS (deconvoluted) m/z calcd: 6510.7; found: $6513.15[\mathrm{M}]^{+} ;$HPLC $\mathrm{t}_{\mathrm{R}}=10.4 \mathrm{~min}$ (Column: analytical $\mathrm{C}_{18} ; \mathrm{A}: \mathrm{H}_{2} \mathrm{O}(0.05 \% \mathrm{TFA}), \mathrm{B}$ : Acetonitrile (0.1\% TFA), 15 to $35 \%$ linear gradient of B into A over $15 \mathrm{~min}, \mathrm{~F}=1 \mathrm{~mL} / \mathrm{min}$ ). 


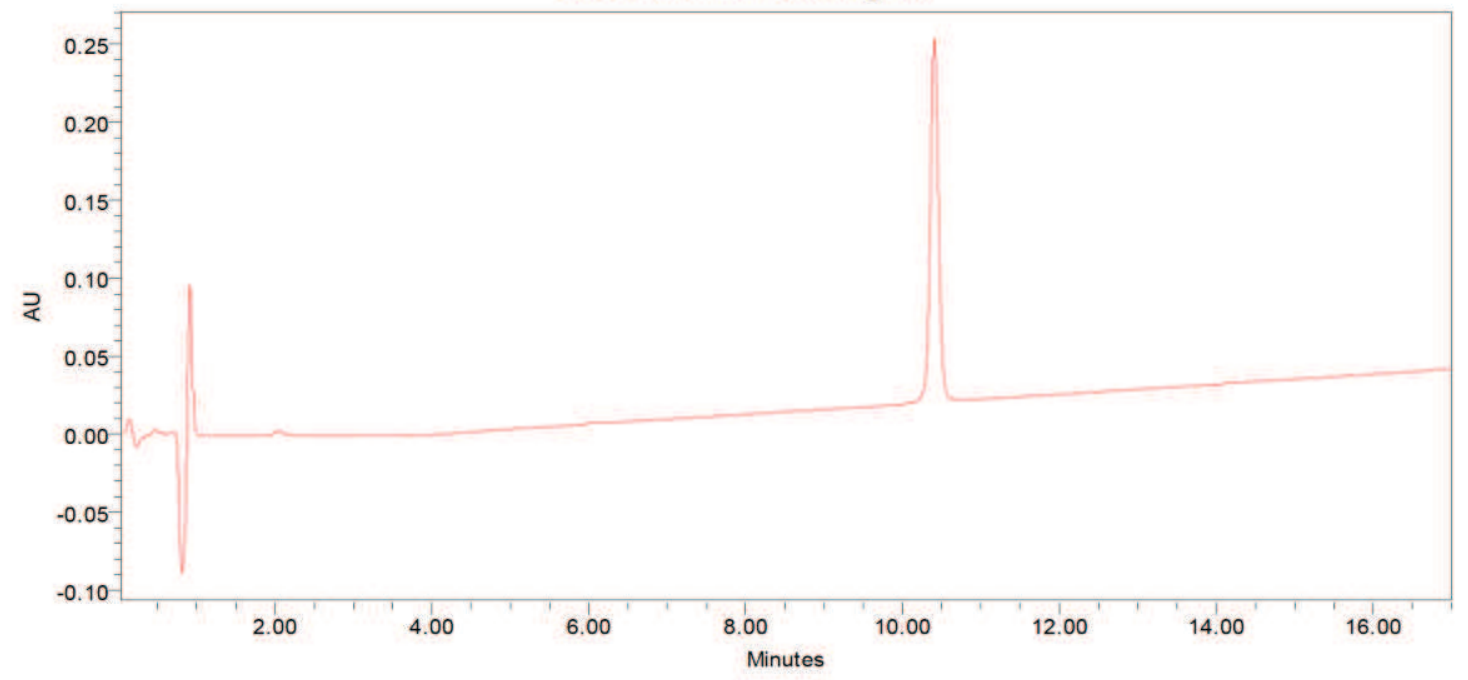

$\mathrm{E}$

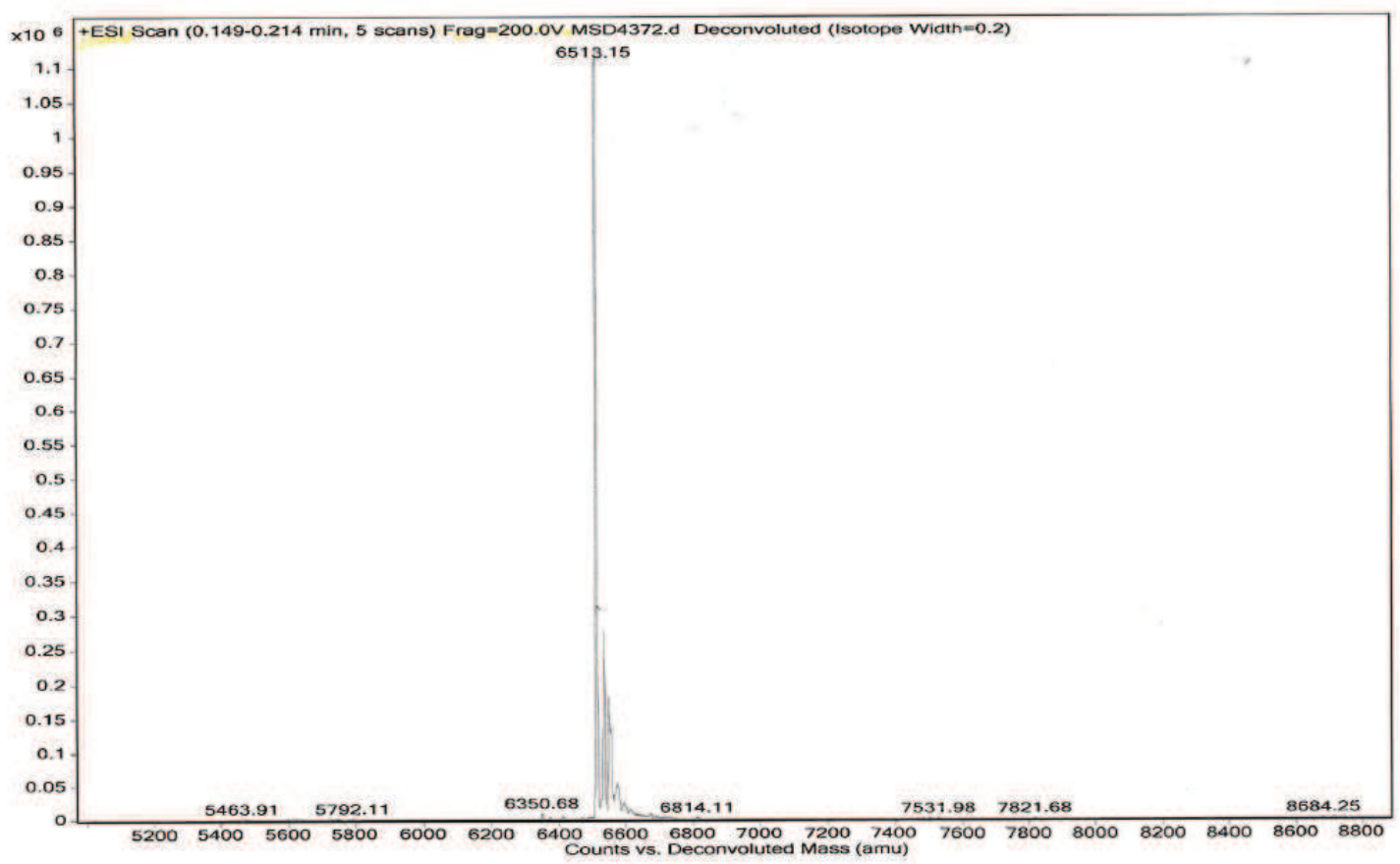

$\mathrm{D}_{1} \mathrm{OE}(\mathrm{D} 4)$

Following the general procedure, using glycodendron $\mathbf{4}$ as starting material, and purification by semipreparative RP-HPLC (column $\mathrm{C}_{18}$ and elution with a linear gradient from 20 to $60 \%$ of solvent $B$ into A over $40 \mathrm{~min}$, at $3 \mathrm{~mL} / \mathrm{min}$ flow rate $\left(\mathrm{A}: \mathrm{H}_{2} \mathrm{O}(0.05 \%\right.$ TFA), B: ACN (0.1\% TFA)), compound $\mathrm{D}_{1} \mathrm{OE}$ (D4) (2.9 mg, $0.50 \mu \mathrm{mol}, 37 \%$ ) was obtained as a white solid.

ESI-MS (deconvoluted) m/z calcd: 5846.83; found: $5846.86[\mathrm{M}]^{+} ;$HPLC $\mathrm{t}_{\mathrm{R}}=9.28 \mathrm{~min}$ (Column: analytical $\mathrm{C}_{18} ; \mathrm{A}: \mathrm{H}_{2} \mathrm{O}(0.05 \%$ TFA), B: Acetonitrile (0.1 \% TFA), 20 to $60 \%$ linear gradient of B into A over $20 \mathrm{~min}, \mathrm{~F}=1 \mathrm{~mL} / \mathrm{min}$ ). 

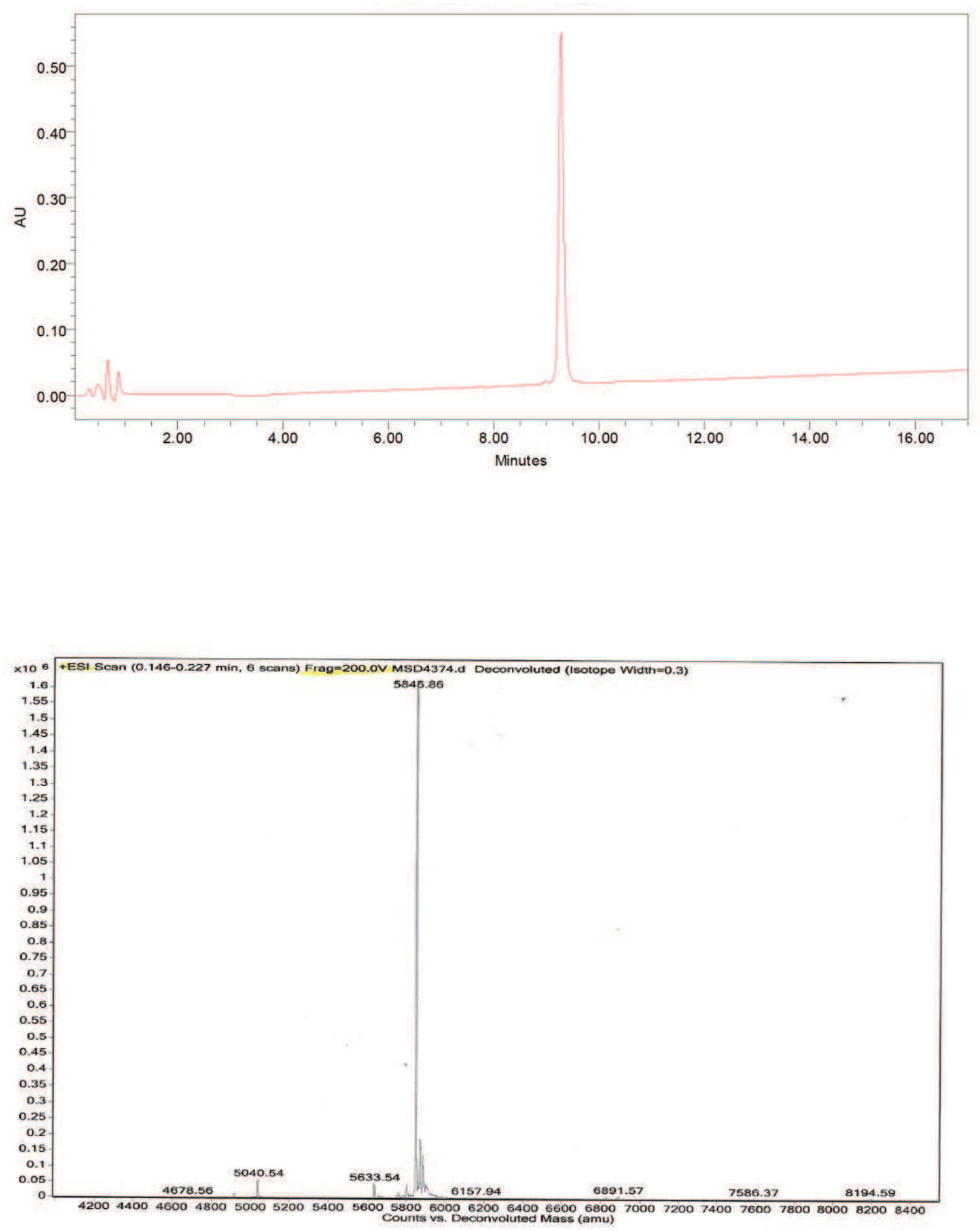

\section{$\mathrm{D}_{1} \mathrm{ManOE}(\mathrm{D} 1)$}

Following the general procedure, using glycodendron $\mathbf{1}$ as starting material, and purification by semipreparative RP-HPLC (column $\mathrm{C}_{18}$ and elution with a linear gradient from 15 to $35 \%$ of solvent $B$ into A over $30 \mathrm{~min}$, at $3 \mathrm{~mL} / \mathrm{min}$ flow rate $\left(\mathrm{A}: \mathrm{H}_{2} \mathrm{O}(0.05 \%\right.$ TFA), B: ACN (0.1\% TFA)), compound D 1 ManOE (D1) (4.8 mg, $0.72 \mu \mathrm{mol}, 59 \%)$ was obtained as a white solid. 
ESI-MS (deconvoluted) $\mathrm{m} / \mathrm{z}$ calcd: 6648.9; found: $6649.04[\mathrm{M}]^{+} ; \mathrm{HPLC}_{\mathrm{R}}=10.57 \mathrm{~min}$ (Column: analytical $\mathrm{C}_{18}$; A: $\mathrm{H}_{2} \mathrm{O}(0.05 \%$ TFA), B: Acetonitrile (0.1 \% TFA), 15 to $35 \%$ linear gradient of B into A over $15 \mathrm{~min}, \mathrm{~F}=1 \mathrm{~mL} / \mathrm{min}$ ).
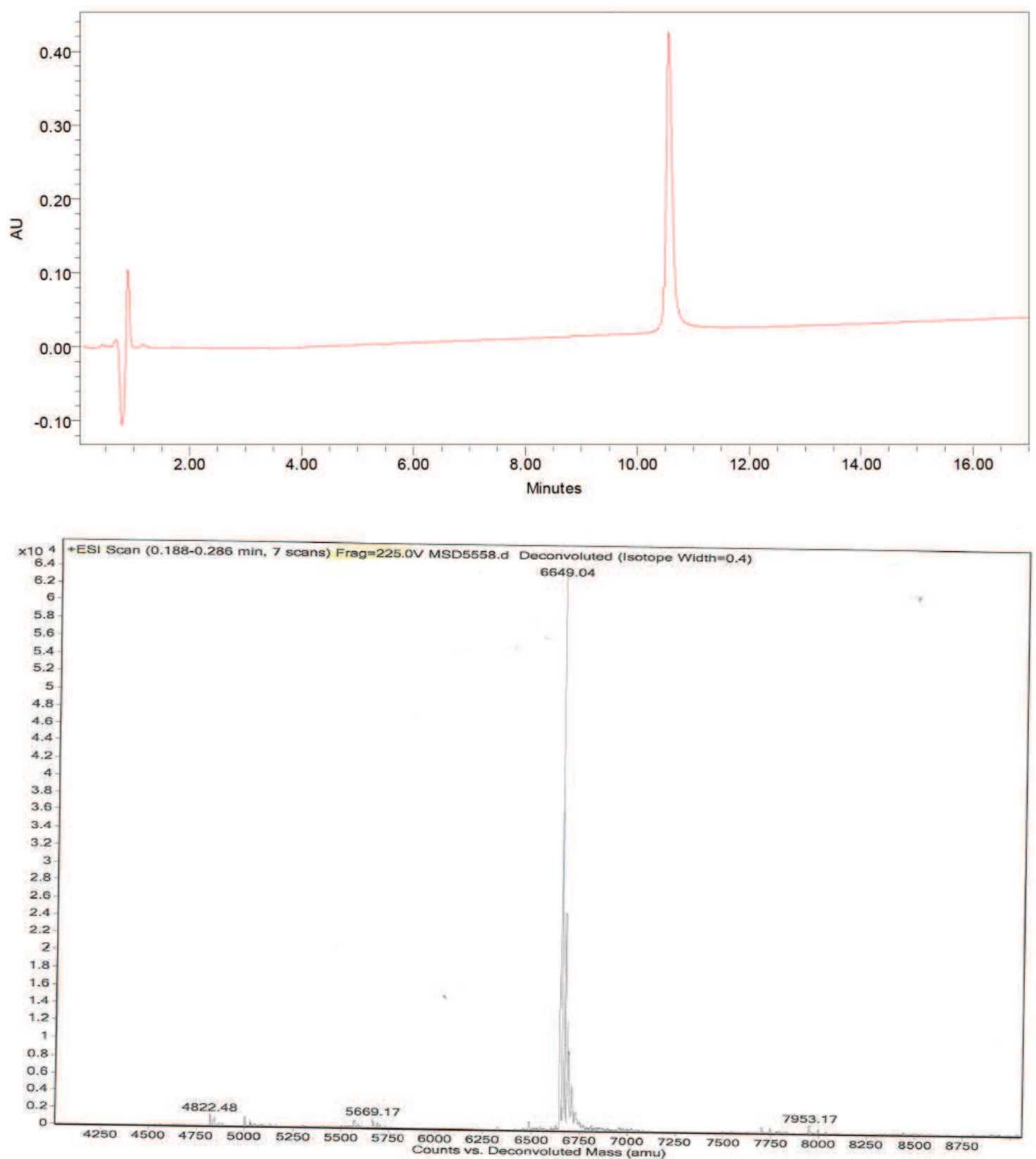

\section{$\mathrm{D}_{1}$ GlcNAc_-O_OE (D3)}

Following the general procedure, using glycodendron $\mathbf{3}$ as starting material, and purification by semipreparative RP-HPLC (column $\mathrm{C}_{18}$ and elution with a linear gradient from 15 to $35 \%$ of solvent $B$ into A over $30 \mathrm{~min}$, at $3 \mathrm{~mL} / \mathrm{min}$ flow rate $\left(\mathrm{A}: \mathrm{H}_{2} \mathrm{O}(0.05 \%\right.$

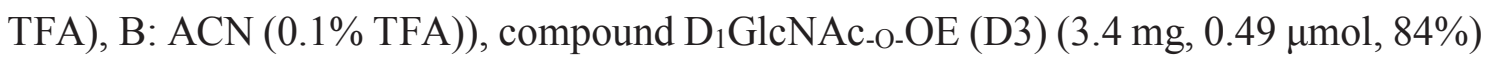
was obtained as a white solid. 
ESI-MS (deconvoluted) $\mathrm{m} / \mathrm{z}$ calcd: 6878.3; found: $6882.80[\mathrm{M}]^{+} ; \mathrm{HPLC}_{\mathrm{R}}=10.15 \mathrm{~min}$ (Column: analytical $\mathrm{C}_{18}$; A: $\mathrm{H}_{2} \mathrm{O}(0.05 \%$ TFA), B: Acetonitrile (0.1 \% TFA), 15 to $35 \%$ linear gradient of B into A over $15 \mathrm{~min}, \mathrm{~F}=1 \mathrm{~mL} / \mathrm{min}$ ).
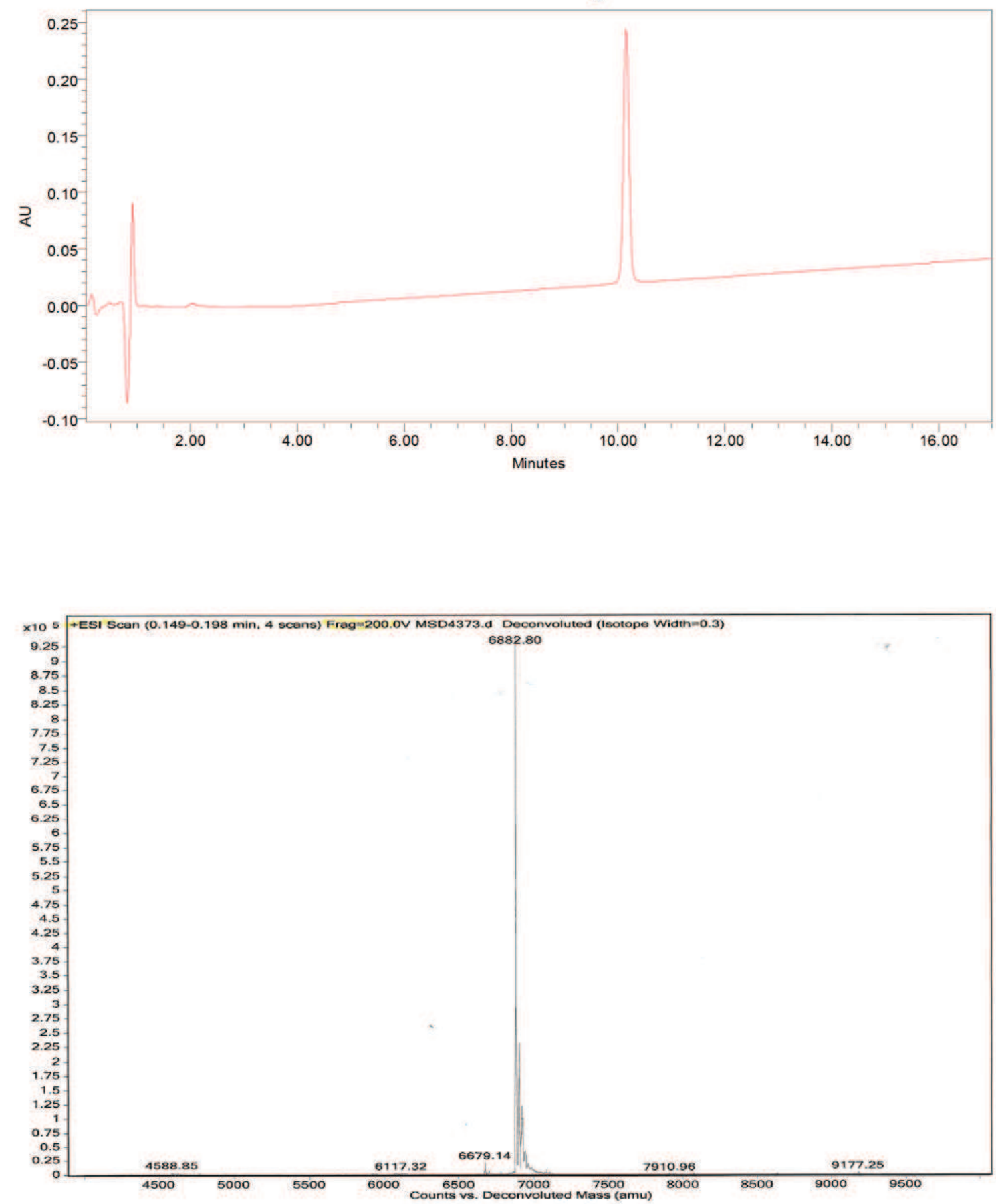


\section{References:}

1. Yang Y, Yu B. Recent Advances in the Synthesis of Chitooligosaccharides and Congeners. Tetrahedron 2014;70:1023-46.

2. Ortega-Muñoz M, López-Jaramillo J, Hernández-Mateo F, Santoyo-González F. Synthesis of Glyco- Silicas by $\mathrm{Cu}(\mathrm{I})$ - Catalyzed "Click- Chemistry" and their Applications in Affinity Chromatography. Adv Synth Catal 2006;348:2410-20.

3. Ribeiro-Viana R, Sánchez-Navarro M, Luczkowiak J, Koipe JR, Delgado R, Rojo R, Davis BG. Virus-like glycodendrinanoparticles displaying quasi-equivalent nested polyvalency upon glycoprotein platforms potently block viral infection. Nat Commun $2012 ; 3: 1-8$.

4.

Song HY, Ngai M H, Song ZY, MacAry PA, Hobley J, Lear MJ. Practical synthesis of maleimides and coumarin-linked probes for protein and antibody labelling via reduction of native disulfides. Biomol Chem 2009;7:3400-6. 
Table S1. Clinical features of subjects included in the study.

\begin{tabular}{cccccc}
$\begin{array}{c}\mathbf{N}^{\mathbf{0}} \\
\text { Subjects }\end{array}$ & Sex & Age & Pollen symptoms & Type reaction & $\begin{array}{c}\text { ImmunoCAPto } \\
\text { Ole e 1 }\end{array}$ \\
A1 & M & 13 & Asthma & Moderate & 25 \\
A2 & M & 75 & Rhinitis & Moderate & 31 \\
A3 & F & 35 & Rhinitis and asthma & Severe & 6.38 \\
A4 & F & 26 & Rhinitis & Mild & 18.4 \\
A5 & F & 47 & Rhinitis and asthma & Moderate/mild & 6.77 \\
A6 & M & 30 & Rhinitis & Mild & 1.2 \\
A7 & M & 37 & Rhinitis & Moderate & 17.2 \\
\hline C1 & F & 56 & NS & - & 0.35 \\
C2 & F & 36 & NS & - & 0.35 \\
C3 & M & 50 & NS & - & 0.35 \\
C4 & M & 48 & NS & - & 0.35 \\
C5 & F & 39 & NS & - & 0.35 \\
\hline
\end{tabular}

A: allergic patient; C: control non-allergic patient; F: female; M: male; NS: non symptoms. 
Table S2. Primers used for RT-PCR amplification of specific genes on Calu-3 cells at ALI.

\begin{tabular}{lll}
\hline Gene & Forward sequence 5'-3' & Reverse primer 5'-3' \\
\hline GAPDH & AAAGGGTCATCATCTCTG & GCTGTTGTCATACTTCTC \\
GST & CGGGCAACTGAAGCCTTTTG & TCAGCGAAGGAGATCTGGTC \\
JUN & GCAAAGAACTTTCCCGGCTG & GGAGAAGCCTAAGACGCAGG \\
NFk $\beta$ & TGAGGATGATGAGAATGGAT & CGGAACACAATGGCATAC \\
\hline GAPDH, glyceraldehyde-3-phosphate dehydrogenase; GST, glutathione S-transferase; JUN, \\
Jun proto-oncogene; NFkB, Nuclear factor kappa B subunit.
\end{tabular}

